\title{
Systemic HER3 ligand-mimicking bioparticles cross the blood-brain barrier reducing intracranial triple- negative breast cancer growth
}

\section{Felix Alonso-Valenteen}

Cedars-Sinai Medical Center

\section{Sam Sances}

Cedars-Sinai Medical Center

HongQiang Wang

Cedars-Sinai Medical Center

Simoun Mikhael

Cedars-Sinai Medical Center

Jessica Sims

Cedars-Sinai Medical Center

Michael Taguiam

Cedars-Sinai Medical Center

Dustin Srinivas

Cedars-Sinai Medical Center

Romny Sanchez

California State University Northridge

Erik Serrano

California State University Northridge

Briana Ondatje

Cedars-Sinai Medical Center

James Teh

Cedars-Sinai Medical Center

Michelle Wong

Cedars-Sinai Medical Center

Kimngan Nguyenle

Cedars-Sinai Medical Center

Tianxin Miao

Cedars-Sinai Medical Center

Rebecca Benhaghnazar

Cedars-Sinai Medical Center

John Yu 
Cedars-Sinai Medical Center

\section{Clive Svendsen}

Cedars-Sinai Medical Center

\section{Ravinder Abrol}

California State University Northridge

Lali Medina Kauwe ( $\sim$ MedinaL@cshs.org )

Cedars-Sinai Medical Center

Article

Keywords:

Posted Date: January 14th, 2022

DOI: https://doi.org/10.21203/rs.3.rs-1139650/v1

License: (c) (i) This work is licensed under a Creative Commons Attribution 4.0 International License. Read Full License 


\title{
Systemic HER3 ligand-mimicking bioparticles cross the blood-brain barrier
} reducing intracranial triple-negative breast cancer growth

\author{
Felix Alonso-Valenteen ${ }^{1}$, Sam Sances ${ }^{2}$, HongQiang Wang ${ }^{3}$, Simoun Mikhael ${ }^{1}$, Jessica Sims ${ }^{1}$, \\ Michael Taguiam ${ }^{1}$, Dustin Srinivas ${ }^{1}$, Romny Sanchez ${ }^{4}$, Erik Serrano ${ }^{1}$, Briana Ondatje ${ }^{2}$, James Teh ${ }^{1}$, \\ Michelle Wong ${ }^{1}$, Kimngan Nguyenle ${ }^{1}$, Tianxin Miao ${ }^{1}$, Rebecca Benhaghnazar ${ }^{1}$, John $\mathrm{Yu}^{3}$, Clive N. \\ Svendsen ${ }^{1,2}$, Ravinder Abrol ${ }^{1,4}$, and Lali K Medina-Kauwe ${ }^{1,5}$ \\ ${ }^{1}$ Department of Biomedical Sciences, ${ }^{2}$ Board of Governors Regenerative Medicine Institute, \\ ${ }^{3}$ Neurosurgical Institute, Cedars-Sinai Medical Center, Los Angeles, CA, USA; ${ }^{4}$ California State \\ University, Northridge, CA, USA; ${ }^{5}$ University of California, Los Angeles, CA, USA.
}

\begin{abstract}
Triple-negative breast cancer (TNBC) lacks selective biomarkers targeted by current clinical therapies and often metastasizes to the brain. Crossing the blood-brain barrier (BBB) and reaching intracranial tumors is a clinical challenge contributing to poor prognoses for patients. The human epidermal growth factor receptor HER3 has emerged as a biomarker of metastasis and may provide a means of therapeutically targeting TNBC. We have developed HER3-targeted biological particles (bioparticles) that exhibit systemic homing to resistant and metastatic breast tumors. Here we show that HER3 is expressed on the brain endothelium and can mediate the passage of bioparticles across the BBB and into intracranial TNBC. Our findings show that the extravasation of systemic bioparticles in mice and in human induced pluripotent stem cell-based BBB chips corresponds to HER3 levels. Furthermore, systemically delivered bioparticles carrying tumoricidal agents reduced the growth of intracranial TNBC in mice and exhibited improved therapeutic profile compared to current therapies.
\end{abstract}

\section{INTRODUCTION}

The blood-brain barrier (BBB) prevents most systemic therapeutics from entering the brain parenchyma and reaching intracerebral tumors, contributing to poor prognoses for patients. ${ }^{1}$ Clinical options are limited to surgery, chemotherapy, and radiation therapy; however, disseminated tumors pose challenges for surgical removal, and untargeted drugs that can reach such tumors also affect healthy tissue. ${ }^{2}$ Targeted antibody therapies such as the HER2/ErbB2 monoclonal antibody trastuzumab (Tz, Herceptin $^{\oplus}$ ) can combat peripheral tumors but cannot cross the BBB thus making them ineffective when such tumors are localized to the brain. ${ }^{3}$ Therapeutic options are further limited for triple-negative breast 
cancer (TNBC), which lacks HER2 and other cell surface biomarkers targeted by current clinical therapies and is brain-metastatic. ${ }^{4}$ Hence, transferring systemic targeted therapies across the BBB and into brain-localized tumors remains a major challenge.

Increased cell surface density of HER3 (or ErbB3) associates with tumor progression, therapeutic resistance and metastasis ${ }^{5}$ including the brain-metastasis of HER2+ and triple-negative breast tumors. ${ }^{6} 7$ HER3 and HER2 belong to the ErbB growth factor receptor kinase family but a nonfunctional kinase domain ${ }^{8}$ makes HER3 a poor target for kinase inhibitors. Nevertheless, several HER3targeted antibodies are being tested in clinical trials for peripheral tumors ${ }^{5,9}$ but may be limited by the resistance of HER3+ tumors to signal-blocking therapies ${ }^{5}$ while the BBB limits antibody access to intracerebral tumors. ${ }^{3}$

Here we demonstrate that a bioengineered tumor-invading protein, HPK, can form cargoencapsulating nano-sized biologically-based particles (bioparticles) that penetrate HER3+ tumors including TNBC. Unlike antibodies, HPK bears a HER3-homing function derived from the natural HER3 ligand neuregulin to mediate tumor-targeting and induce endocytic uptake. HPK also utilizes the capsidforming and endosomal disrupting functions of an adenovirus-derived capsid protein to encapsulate and deposit macromolecular cargo into HER3-expressing cells.

These studies show that systemic HPK bioparticles not only home to metastatic HER3+ tumors but also enter the brain, in contrast to free cargo, HER2 antibodies, and protein lacking neuregulindirected delivery. We subsequently found that HER3 is prominently expressed on both mouse and human brain endothelium and associates with systemic bioparticle transfer into the brain parenchyma. The association of HER3 with brain metastasis ${ }^{9}$ led us to test whether HER3 can transport systemic HER3-homing bioparticles across the BBB and into intracerebral TNBC tumors as well as reduce intracerebral tumor growth when delivering tumoricidal agents compared to currently used clinical therapy. Mice with intracerebral TNBC implants served as preclinical models of secondary brainmetastasized TNBC tumors.

The role of HER3 on the brain endothelium has not been widely examined but may serve to ferry circulating neuregulins across the BBB. Neuregulins facilitate neuronal maturation, myelination, and repair ${ }^{10}$ hence a route mediating systemic neuregulin passage into the brain could be engaged by HPK bioparticles. Accordingly, we also examined HER3 localization in disease-free mouse and human brain specimens and interrogated the contributions of HER3 toward bioparticle extravasation in mice and in a reconstituted human BBB using an induced pluripotent stem cell (iPSC)-derived organ-on-chip, or BBB chip. These models enabled rigorous evaluation of HER3-targeted biocarriers in combating brainlocalized tumors and identified a new route for systemic macromolecular delivery into the brain. 
Cells. MDA-MB-231, 4T1, BT-549 and MDA-MB-435 cell lines were originally obtained from the American Type Culture Collection and were maintained at $37^{\circ} \mathrm{C}$ with $5 \% \mathrm{CO}_{2}$ under mycoplasma-free conditions in complete medium (DMEM supplemented with $10 \%$ fetal bovine serum, $100 \mathrm{U} / \mathrm{mL}$ penicillin, and $100 \mu \mathrm{g} / \mathrm{mL}$ streptomycin).

Genomic analyses of HER3 expression in normal and tumor tissues. All genomic datasets used in our studies are publicly available. The R2 Genomics Analysis and Visualization Platform (http://r2.amc.nl) was used to access the Roth database of normal tissues, The Cancer Genome Atlas (TCGA) database (TCGA-1097) of breast invasive carcinomas, and the Brown-198 database of TNBC samples. The normal database was filtered to only include normal breast tissue (breast, nipple, and breast adipose). HER3 (ERBB3), TfR (TFRC), and GLUT1 (SLC2A1) genes were used to interrogate the Normal Endothelial cell (HUAEC/HUVEC)-Luttun-38 and TNBC metastatic brain tumors-Biernat-71 databases and all normal R2 databases, excluding CNS tissue. The latter encompasses the following individual databases: adrenal (Various-13); B cell (Comerma-24; Johnsen-38; Jima-12; Kauppinen-38; Nussenzweig-8); blood (Tompkins-857; Uyhelji-555; Jarvela-96; Sindhi-26;Tangye-14; Yamaguchi-30; Yamaguchi-30 fRMA; Fioretos-16; Novershtern-211; Villani-1244; Villani-1140); colon (Marra-32; Vivier4); developmental (embryonic, Tanavde-136; fetal, Wang-4089; fetal, Wang-5290; fetus, Bianchi-40; HES iPSC, Linnarsson-337; HSC, Ogic-21; Stem cell fetal, Xian-24 huex10p; Stem cell fetal, Xian-24 huex10t; embryogenesis, Yi-18; Stem cells, Linnarsson-1715); endothelial (Luttun-38); Epithelial (Shelhamer-9); fallopian tube (Shaw-24); fibroblasts (Mazda-6); leukocytes (Clark-108; Clark-114; Matthes-33 fRMA; Matthes-33); liver (McGilvray-8444; McGilvray-4059); lymphocytes (Goerdt-20; Franken-440; Franken-352; Franken-440; Franken-352; Lye-154; Lye 154 fRMA); macrophages (Salazar-44); mesenchymal (Wezel-15 huex10p; Wezel-15 huex10t); monocytes (PBM-26); muscle (Gordon-22; Hofman-121 u133a; Hofman-121 u133b; Asmann-40); pancreatic (Groop-89; Taneera-63); placenta (Bammler-12); platelets (Shaw-154); skeletal (Stephan-4); spermatogonia (Brinster-6; Spiess8); T cell (Wicker-35); and thymus (Ferrando-21). Gene expression data is represented as a $\log _{2}$ transformation.

Flow cytometry detection of HER3. To detect HER3 surface receptor levels, human [BT549, MDA-MB-231(+) and MDA-MB-231(-)] and murine (4T1) breast cancer cells were incubated with $10 \mathrm{~mL}$ lifting buffer (0.5 M EDTA in Phosphate Buffered Saline, PBS) for $1 \mathrm{~h}$ at $37^{\circ} \mathrm{C}$, with gentle agitation. Detached cells were collected, washed with PBS++ (PBS with $1 \% \mathrm{MgCl} 2$ and $1 \% \mathrm{CaCl} 2$ ), pelleted, resuspended in PBS, counted using the forward scatter of unstained samples and aliquoted into tubes containing $2 \times 10^{6}$ cells in $2 \mathrm{~mL}$ each. Cells were fixed with 4\% Paraformaldehyde (PFA) for $10 \mathrm{~min}$, 
107

108

109

110

111

112

113

114

115

116

117

118

119

120

121

122

123

124

125

126

127

128

129

130

131

132

133

134

135

136

137

138

139

140

141

rinsed with PBS (3 × $5 \mathrm{~min})$, and suspended in blocking buffer (1\% Bovine Serum Albumin, BSA, in PBS) at room temperature (RT). After $1 \mathrm{~h}$, the cells were divided into two tubes, each containing $1 \times 10^{6}$ cells, and rinsed with PBS (2 × $5 \mathrm{~min}$ ). Stained samples received Alexa Fluor-488-conjugated anti-HER3 antibody (FAB3481G; R\&D Systems, Minneapolis, MN), at 1:100 in blocking buffer for $1 \mathrm{~h}$ at RT in the dark and compared to unstained samples incubated in blocking buffer. Both samples were rinsed with PBS (3 $\times 5 \mathrm{~min})$ and analyzed using a Moxi GO benchtop flow cytometer (Orflo Technologies, Ketchum, ID).

Patient-derived tissue. De-identified surgical specimens of two independent breast cancer tissues and one normal breast tissue were obtained by informed consent under IRB-approved protocol \#29973. Resected breast tissues were immediately placed in cold, sterile DMEM after excision and cut into 2-4 mm pieces before undergoing enzymatic and mechanical dissociation using the gentleMACS ${ }^{\text {TM }}$ Octo Dissociator multitissue kit and protocol (Miltenyi Biotec). Resuspended cells were then promptly plated into flasks, multiwell plates, or chamber slides for the indicated treatments. Human brain specimens were received from three fresh male cadaver brains ages 68, 71 and 76 . (Tissue for Research, Ltd.) Samples were preserved in $10 \%$ buffered formalin.

Immunocytofluorescence/immunohistofluorescence. Cells were washed 3-4 times with 1\% $\mathrm{MgCl} 2$ in PBS, then fixed with 4\% paraformaldehyde in PBS for $15 \mathrm{~min}$ at room temperature. Coverslips were washed three times with PBS, then incubated with $50 \mathrm{mM}$ ammonium chloride in PBS for 5 min at room temperature. Cells on coverslips were washed again three times in PBS, then incubated in $0.1 \%$ Triton X-100 in PBS for 5 min at room temperature followed by immunostaining protocol described below. Tissues were paraffin-embedded, sectioned, and mounted onto slides. The slides were deparaffinized by incubation in a dry oven for $1 \mathrm{~h}$, washed with xylene $5 \times 4$ min each, and sequentially rinsed in $100 \%$, $95 \%, 90 \%, 80 \%$, and $70 \%$ ethanol, $2 \times 3$ min each. The slides were then submerged in water. Epitope retrieval was performed by incubating the slides for $30 \mathrm{~min}$ at $37^{\circ} \mathrm{C}$ in $10 \mathrm{mM}$ Tris, $1 \mathrm{mM}$ EDTA, $0.05 \%$ Tween 20, pH 9.0. Peroxidase inactivation was performed using $3.0 \% \mathrm{H}_{2} \mathrm{O}_{2}$ for 30 minutes.

Slides were blocked in $1 \%$ BSA for 2 hours and, where indicated, stained with antibodies against claudin5 (Invitrogen 35-2500 1:50), Ad5 (Abcam ab6982 1:100), HIS-tag (Qiagen 34610 1:100), CAV1 (caveolae marker, ab2910), and HER3 (R\&D Systems AF4518 1:400) at $4^{\circ} \mathrm{C}$ overnight followed by washing and staining with species appropriate fluorescent secondaries for 2 hours at room temperature in the dark. Brain sections were incubated in True Black lipofuscin autofluorescence quencher (Goldbio cat \# TBH-250-1). Slides were counterstained and mounted with 4'6-diamidino-2-phenylindole (DAPI)containing Prolong Antifade (Thermofisher). 
TUNEL Assay. Terminal deoxynucleotidyl transferase dUTP nick-end labeling (TUNEL) assays was performed, according to the manufacturer's instructions (Roche). Following treatment, slides were counterstained and mounted with 4'6-diamidino-2-phenylindole (DAPI)-containing Prolong Antifade (Thermofisher). Images of stained tissues were captured using a Leica SPE laser-scanning confocal microscope and Molecular Devices ImageXpress Pico, where indicated. Images were analyzed using three independent fields quantifying positive cell signals above threshold determined by unstained controls with equal exposure.

Recombinant protein production. Recombinant HPK proteins were produced from the pRSETaffinity purification of fusion proteins. The plasmid construct encodes the receptor-binding region of neuregulin-1a (amino acids 35-239, comprising the Ig-like and EGF-like domains) ${ }^{11}$ expressed as an amino-[N]-terminal fusion to the penton base sequence followed by a carboxy-[C]-terminal decalysine. ${ }^{12}$ To produce the fusion protein in bacteria, $50 \mathrm{~mL}$ cultures of Escherichia coli BLR(DE3)pLysS transformed with the indicated pRSET constructs were grown to turbidity at $37^{\circ} \mathrm{C}$, with vigorous agitation. Cultures were expanded into $500 \mathrm{~mL}$ cultures and induced with $0.4 \mathrm{mM}$ isopropyl $\beta$-d-1thiogalactopyranoside (IPTG) once the culture reached an optical density at $600 \mathrm{~nm}\left(\mathrm{OD}_{600}\right)$ of 0.6-0.8. Incubation continued $3 \mathrm{~h}$ after induction, after which the cells were pelleted via centrifugation for 20 minutes at 2,500 $\mathrm{G}$ and resuspended in $5 \mathrm{~mL}$ lysis buffer $\left(50 \mathrm{mM} \mathrm{NaH}_{2} \mathrm{PO}_{4} ; 50 \mathrm{mM} \mathrm{NaCl} ; \mathrm{pH}\right.$ 8) containing $0.1 \%$ Triton X-100 and $1 \mathrm{mM}$ phenylmethylsulfonyl fluoride (PMSF). After one freeze-thaw cycle, $10 \mathrm{mM} \mathrm{MgCl} 2$ and $0.01 \mathrm{mg} / \mathrm{mL}$ DNase I were added, and lysates were gently agitated at RT until viscosity was reduced. Lysates were then transferred to ice, followed by the addition of $\mathrm{NaCl}$ and imidazole to $1 \mathrm{M}$ and $10 \mathrm{mM}$ final concentrations, respectively. Lysates were clarified by centrifugation at $4^{\circ} \mathrm{C}$, followed by fast protein liquid chromatography (FPLC) affinity purification, programmed with a stepped gradient of imidazole (ranging from 0-500 mM) in $50 \mathrm{nM} \mathrm{NaH}_{2} \mathrm{PO}_{4}$ and $1 \mathrm{M} \mathrm{NaCl}$. Fractions containing eluted protein (approximately $92 \mathrm{kDa}$ by immunoblot) were buffer exchanged by ultrafiltration in storage buffer (20 mM HEPES, pH 7.4, $150 \mathrm{mM} \mathrm{NaCl}, 10 \%$ glycerol).

Particle assembly. Near-infrared (NIR) particles were generated by combining HPK with an Alexa Fluor ${ }^{\circledR} 680$ end-labeled single-stranded oligonucleotide (ssODN) with the sequence 5'-Alex680NCGCCTGAGCAACGCGGCGGGCATCCGCAAG (obtained from Integrated DNA Technologies). A 4:1 molar ratio of HPK:SSODN was incubated at RT for at least 20 min in HEPES-buffered saline (HBS). Particles were filtered twice using 100-kDa molecular weight cutoff (mwco) ultrafiltration devices. Filtrates and retentates were assessed for protein concentration using a Bradford assay, and the sSODN payload was assessed by fluorescence at $680 \mathrm{~nm}$ using a Spectramax M2 spectrophotometer.

To generate HerDox particles, non-labeled oligonucleotides containing the same sequence as 
ssODN and its reverse complement were annealed to form oligonucleotide duplexes, as described previously. ${ }^{13}$ HerDox particles were then generated by combining oligonucleotide duplexes (dsODN) with doxorubicin (Dox) at a molar ratio of 1:10 dsODN:Dox for $10 \mathrm{~min}$ at RT in Tris-buffered saline (TBS; 10 $\mathrm{mM}$ Tris- $\mathrm{HCl}, \mathrm{pH} 7.4 ; 150 \mathrm{mM} \mathrm{NaCl}$ ), with inversion and agitation. HPK was added at a 4:1 ratio of HPK:dsODN:Dox. The mixtures were subjected to ultrafiltration using 100-kDa mwco membranes to isolate assembled particles from unassembled components. The dsODN concentration was quantified by spectrophotometric absorbance at $260 \mathrm{~nm}$ after the heparin-mediated release of nucleic acids, as previously described. ${ }^{12}$ The Dox concentration was determined using absorbance at $480 \mathrm{~nm}$, followed by the application of Beer's Law using the extinction coefficient of Dox $=8030 \mathrm{M}^{-1} \mathrm{~cm}^{-1}$. The protein content

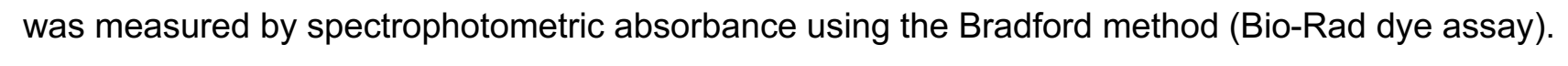

Electron microscopy. Particles were prepared for transmission electron microscopy (TEM) by dispersion in hexane followed by dropping onto an amorphous carbon coated grid. Fixed samples were imaged using a TF20 (FEI Tecnai) transmitting electron microscope fitted with a field emission gun operated at $200 \mathrm{kV}$. Images were acquired using a TIETZ F415MP CCD camera and processed using TIETZ Tomography package.

Structural modeling and molecular dynamics (MD) simulation. The HPK monomeric and pentameric structures were generated, as previously described. ${ }^{12}$ The HPK monomeric and pentameric structures were generated, as previously described. ${ }^{12}$ A truncated version of the HPK monomer and pentamer was built (tHPK) to model the effect of $\mathrm{pH}$ on the titratable residues in the penton base core of the HPK pentamer. Protein sequence of tHPK monomer was: TGGRNSIRYSELAPLFDTTRVYLVDNKS TDVASLNYQNDHSNFLTTVIQNNDYSPGEASTQTINLDDRSHWGGDLKTILHTNMPNVNEFMFTNKFKA RVMVSRLPTKDNQVELKYEWVEFTLPEGNYSETMTIDLMNNAIVEHYLKVGRQNGVLESDIGVKFDTRN FRLGFDPVTGLVMPGVYTNEAFHPDIILLPGCGVDFTHSRLSNLLGIRKRQPFQEGFRITYDDLEGGNIPA LLDVDAYQASLKDDTEQGGGGAGGSNSSGSGAEENSNAAAAAMQPVEDMNDHAIRGDTFATRAEEKR AEAEAAAEAAAPAAQPEVEKPQKKPVIKPLTEDSKKRSYNLISNDSTFTQYRSWYLAYNYGDPQTGIRS WTLLCTPDVTCGSEQVYWSLPDMMQDPVTFRSTRQISNFPVVGAELLPVHSKSFYNDQAVYSQLIRQFT SLTHVFNRFPENQILARPPAPTITTVSENVPALTDHGTLPLRNSIGGVQRVTITDARRRTCPYVYKALGIVS PRVLSSRT.

The pentameric core structure of the tHPK particle was investigated under 4 different $\mathrm{pH}$ conditions $(\mathrm{pH}=7,5,3,1)$. The protonation states of the titratable residues were obtained from the propKa server ${ }^{14,15}$ yielding a corresponding net charge on the tHPK bioparticle at different $\mathrm{pH}$ values: -60 at $\mathrm{pH} 7,-5$ at $\mathrm{pH} 5,+255$ at $\mathrm{pH}=3$, and +300 at $\mathrm{pH}=1$. The tHPK molecular structures at $4 \mathrm{pH}$ levels (tHPK7, tHPK5, tHPK3, and tHPK1) were relaxed using implicit solvent generalized born molecular dynamics (MD) simulations with the AMBER ff14SB force field ${ }^{16}$ that are part of the AMBER simulation 
214 package ${ }^{17}$. The protonation states of the titratable residues were set for the specific $\mathrm{pH}$ values and not

215 allowed to change during the biophysical simulations. All bioparticle structures were relaxed using 10

216 nanoseconds of simulation time. The pH 5 and 7 (tHPK5/tHPK7) bioparticles were simulated for an

217 additional phase of 50 nanoseconds as $\mathrm{pH} 1$ and 3 (tHPK1/tHPK3) pentameric bioparticles broke apart

218 into monomers within the first phase of 10 nanoseconds.

219

Receptor binding. To analyze HPK binding to tumor cells, cells were plated at $1 \times 10^{4} /$ well in 96 well plates and maintained for $24 \mathrm{~h}$. Cells were incubated on ice to pre-chill cells, and $1.5 \mu \mathrm{g}$ of HPK diluted in chilled complete medium was added to each well. Ligand blocking was performed by preadsorbing HPK with soluble human HER3 peptide (Sino Biological) at 10× molar excess in PBS before addition to cells. Cells were incubated on ice for $1 \mathrm{~h}$ to promote binding but not uptake, then thoroughly washed with PBS++ (PBS with 1\% MgCl2 and 1\% CaCl2), fixed with 4\% PFA under non-permeabilizing conditions (to detect cell surface proteins), and processed for enzyme-linked immunosorbent assay (ELISA) per manufacturer's instructions (Thermo cat. Number 00-4201-56) followed by crystal violet (CV) staining for normalization according to cell number. CV staining was carried out by removing cell media and washing cells with PBS containing $0.01 \% \mathrm{Mg}++$ and $0.01 \% \mathrm{Ca}++$. The PBS was aspirated and each well was stained with $0.1 \%$ Crystal Violet at RT for $15 \mathrm{~min}$. The cells were then washed in PBS with $\mathrm{Mg}++/ \mathrm{Ca}++4$ times. After the final wash, each well received $100 \mathrm{uL} 95 \%$ ethanol to release the $\mathrm{CV}$. The plate was incubated at RT for 10 minutes before the absorbance at $590 \mathrm{~nm}$ was measured.

Subcellular fractionation. Subconfluent (70\% confluency) HER3+ MDA-MB-435 tumor cells grown in complete media were rinsed with 1× PBS, serum-starved in Buffer A [Dulbecco's modified Eagle medium (DMEM) containing 20 mM HEPES, pH 7.4; $2 \mathrm{mM} \mathrm{MgCl}_{2}$; and 3\% bovine serum albumin (BSA)] for 1 hour at $37^{\circ} \mathrm{C}$, rinsed with $1 \times$ PBS, detached with $2 \mathrm{mM}$ EDTA/PBS, and neutralized with double the volume of $1 \times$ PBS ++ . An aliquot containing $6 \times 10^{6}$ cells was washed with PBS and resuspended in $0.7 \mathrm{~mL}$ Buffer A containing $5 \mathrm{nM}$ indicated proteins (quantified by Bradford Assay). Cells were incubated with rocking for 1 hour at $4^{\circ} \mathrm{C}$ to promote receptor binding but not uptake, followed by transfer to $37^{\circ} \mathrm{C}$ to promote synchronized cell uptake. At the indicated time points, cells were pelleted (10 min, $5000 \mathrm{rpm}, 4^{\circ} \mathrm{C}$ ) and washed in a mildly acidic buffer ( $1 \mathrm{~mL}$ of $\left.1 \times \mathrm{PBS}, \mathrm{pH} 6\right)$ for 5 minutes to remove the remaining cell surface protein. Cell pellets were then rinsed with $1 \times$ PBS and processed for subcellular fractionation (Qproteome Cell Compartment Kit, Qiagen; following the manufacturer's protocol). Indicated fractions were isolated, and protein precipitation was performed by incubation in 4 volumes of ice-cold acetone for 15 minutes, followed by pelleting (10 min, 14,000 rpm, $4^{\circ} \mathrm{C}$ ), the removal of the supernatant, and resuspension in storage buffer (10\% glycerol and $5 \%$ SDS in $\left.\mathrm{dH}_{2} \mathrm{O}\right)$. Samples were subject to reducing sodium dodecyl sulfate-polyacrylamide gel electrophoresis (SDS-PAGE) and immunoblotted using antibodies recognizing recombinant protein (anti-NRG1; NRG1abcam ab180808, 
1:5000 dilution in 5\% milk) and corresponding fraction controls: cytosolic (GAPDH; R\&D Systems,

MAB5718, 1:10000 in 3\% BSA); cytoskeletal ( $\beta$-actin; R\&D Systems, MAB8929, 2:10000 in 3\% BSA); and membrane (TIM23; BD Biosciences, 611222, 6:10000 in 3\% BSA). Primary incubation was performed overnight at $4^{\circ} \mathrm{C}$ followed by incubation with anti-rabbit or anti-mouse HRP-containing secondary at room temperature for 2 hours (abcam-goat anti rabbit ab6721 and goat anti mouse AB6789 respectively). Immunoblots were imaged using the high sensitivity setting on a Bio-Rad chemidoc imager.

Intracellular trafficking. The intracellular trafficking of HPK was evaluated following our previously established procedures, ${ }^{12}$ with the following modifications: 12 -well plates containing 10,000 cells/well plated on coverslips were briefly pre-chilled and exposed to $7 \mu \mathrm{g} \mathrm{HPK}$ per well in Buffer A for 1 $\mathrm{h}$ to promote receptor binding but not internalization. Equivalent samples received $100 \mathrm{nM}$ bafilomycinA1 in Buffer A for 30 min before adding HPK. Plates were then transferred to $37^{\circ} \mathrm{C}$ to promote synchronized uptake and intracellular trafficking. Cells were fixed at indicated time points after warming, processed for the immuno-identification of HPK using an antibody that recognizes the polyhistidine tag (RGS-His antibody; Qiagen 1:100), and counterstained with DAPI. Images were acquired using a highthroughput digital microscope (Molecular Devices ImageXpress ${ }^{\circledR}$ Pico Automated Cell Imaging System) using a 40x magnification lens. Exposure times for each fluorescence wavelength remained fixed to compare between treatments and timepoints. Where indicated, vesicular-like sequestration of HPK was quantified by subtracting the measured integrated density (Int D) of extravesicular (e) from the vesicular (v) regions normalized by $v$, or $\left(\right.$ Int $\left.D_{v}-\operatorname{lnt} D_{e}\right) / \operatorname{lnt} D_{v}$.

Endosome maturation staining antibodies against RAB7 and early endosome antigen 1 (EEA1) were purchased from Abcam (ab50533 and ab206860, respectively). Samples were imaged using a Leica SPE laser-scanning confocal microscope. Acquired images were imported and separated into individual channels. Individual cells in selected channels were delineated, and pixel overlap was evaluated using ImageJ.

276

Isothermal titration calorimetry. Isothermal titration calorimetry (ITC) experiments were performed using a MicroCal PEAQ-ITC at $25^{\circ} \mathrm{C}$. Heat changes during assembly of HPK with ssODN were measured after suspending ssODN in RNA annealing buffer $(10 \mathrm{mM}$ Tris- $\mathrm{HCl}, \mathrm{pH} .7 .5 ; 50 \mathrm{mM}$ $\mathrm{NaCl}$, and $1 \mathrm{mM}$ EDTA, in ultrapure nuclease-free water.).

To avoid buffer mismatch, HPK was buffer exchanged into the same RNA annealing buffer. The ssODN $(300 \mu \mathrm{L}$ at $1.0 \mu \mathrm{M})$ was placed in a stirred cell and titrated with $5.4 \mu \mathrm{M}$ HPK at $2 \mu \mathrm{L} \mathrm{HPK} /$ titration in a 2.5 min injection to allow for the titration peak to return to baseline. The dissociation constant $\left(\mathrm{K}_{\mathrm{d}}\right)$ was calculated using MicroCal PEAQ-ITC analysis software and Prism GraphPad software, using the one-site model. Control experiments included titrating HPK into buffer, buffer into ssODN, and buffer into 
buffer to ensure that measured changes were not due to buffer mismatches or other artifacts. The three controls were combined into a composite and used to subtract the heat of dilution and background noise from the baseline. ITC measurements of the HPK assembly with dsODN and the HerDox assembly are described in the Supplementary Methods.

290

Dynamic light scattering (DLS). A Malvern ZEN 3600 Zetasizer Nano was used for DLS analyses. A typical analysis comprised three or more measurements per sample, with each measurement comprising 100 runs and an average of $34 \mathrm{~K}$ particle counts/sec (kpcs). The reported average is the particle size determination parameter, which yields the most frequent particle size detected in the sample while accounting for intensity fluctuations associated with larger particles. The intensity of the particles was computed via Zetasizer Software version 7.01, which applies the StokesEinstein equation to correlate changes in the scattering intensity and particle movements.

Serum digest (protection) assay. Free dsODN alone $(60 \mathrm{pmol})$ or preincubated with HPK $(2 \mu \mathrm{g}$ for $30 \mathrm{~min}$ at RT) was incubated in whole (100\%) active mouse serum at $0^{\circ}$ and $37^{\circ} \mathrm{C}$ for $1 \mathrm{~h}$ and then subjected to agarose gel electrophoresis followed by ethidium bromide staining to visualize intact dsODN. Heat Inactivated (H.I.) serum was used as a control.

BBB chip. The organ-on-a-chip is composed of a flexible polydimethylsiloxane (PDMS) elastomer that contains two closely apposed and parallel micro-channels $(1 \times 1 \mathrm{~mm}$ top channel and $1 \times$ $0.2 \mathrm{~mm}$ bottom channel) ${ }^{18}$ separated by a porous, flexible PDMS membrane (50- $\mu \mathrm{m}$-thick, with 7- $\mu \mathrm{m}$ diameter pores, spaced $40 \mu \mathrm{m}$ apart, resulting in $2 \%$ porosity over a surface area of $0.171 \mathrm{~cm} 2$ separating the two channels) coated with matrigel in the top channel, and collagen-fibronectin ECM in the bottom channel. Cell aggregates (“EZ-spheres”) ${ }^{19}$ were derived from human cells obtained through IRB \#21505. To generate BBB chips, EZ-spheres containing induced pluripotent stem cell (iPSC)-derived neural progenitor cells (NPCs) were dissociated into single cells using accutase and were seeded into the top channel ("brain channel") at a density of $1.25 \times 10^{6}$ cells $/ \mathrm{mL}$ in terminal differentiation media [TDM, containing Rock inhibitor 1:2000 (Stemgent)]. NPCs were allowed to settle for $2 \mathrm{~h}$ and were then flushed with TDM without Rock inhibitor. Media was replaced with $100 \mu \mathrm{L}$ TDM every other day. Five days later, human induced pluripotent stem cell-derived brain microvascular endothelial like cells (iBMECs) were seeded into the bottom channel ('vascular channel") at $15 \times 10^{6}$ cells $/ \mathrm{mL}$ in S3 BMEC medium containing Rock inhibitor (1:2000) and inverted for $2 \mathrm{~h}$. A second seeding was performed after 2 $\mathrm{h}$ using the same protocol without inversion for $2 \mathrm{~h}$. Following the second incubation period, the BBB chips were flushed with S3 BMEC medium without Rock inhibitor. The following day, chips were flushed with fresh TDM and S4 BMEC medium. The following day, the chips were added to Emulate, Inc. pods and placed on an active flow of $30 \mu \mathrm{L} / \mathrm{h}$. Chips were validated via paracellular permeability assays using 
dextran-FITC overnight to confirm the barrier function of the chips under flow. Validated BBB chips were treated with NNCs at a concentration equating to $1 \mu \mathrm{g} / \mathrm{mL}$ of HPK that was passed through the endothelial channel with or without 10:1 blocking peptide purchased commercially from Sinobiological (10201-H08H). After 4 hours of constant flow, the chips were fixed using 4\% PFA and subjected to immunocytofluorescent staining.

Sandwich ELISA. Non-tissue culture-treated polystyrene plates were pre-coated using rabbit anti-Ad5 (Abcam- ab6982) diluted in sodium bicarbonate pH 9.2. Plates were then blocked using 3\% BSA. After washing three times with PBS, BBB effluents were incubated overnight. Signal was detected using mouse anti-His antibody from Qiagen (Cat No./ID: 34660 1:500). Anti-mouse horseradish peroxidase (HRP) was used for colorimetric development (Cat No./ID- A8924 1:1000). A650 reads were started 15 minutes after the addition of TMB. Once developed and read using Molecular Devices SpectraMAx M2, the reaction was stopped by adding $1 \mathrm{~N} \mathrm{HCl}$, and the A450 was acquired. An HPK standard curve was processed in parallel to quantify HPK NNCs collected from BBB chip effluents. (emaciation, prominent skeletal structure, little/no flesh cover, visible and distinctly segmented

Animal subjects. Immunodeficient (NU/NU) and immunocompetent (BALB/c) mice were obtained from Charles River Laboratories, Inc. All procedures involving mice were performed following IACUC-approved protocols \#6037 and \#5790, in accordance with the institutional and national Guide for the Care and Use of Laboratory Animals. The criteria for euthanasia included tumor ulceration, interference with ambulation and access to food and water, or body condition score (BCS) of less than 2 vertebrae). ${ }^{20,21}$

Tumor models. Peripheral breast tumor models used for the biodistribution studies were established in 6-week-old female mice. For xenograft models, immunodeficient (NU/NU) mice received bilateral flank implants of JIMT-1 human HER2+ tumor cells $\left(1 \times 10^{7}\right.$ cells/implant). For immunecompetent models bearing peripheral TNBC tumors, BALB/c mice received bilateral mammary fat pad injections of 4T1-LucGFP cells $\left(1 \times 10^{4}\right.$ cells/injection in $100 \mathrm{~mL}$ PBS). Tumor volumes (height $\times$ width $\times$ depth) were monitored approximately 3 times/week under single-blinded conditions (treatment groups unknown to the individual acquiring measurements). Mice were randomized at tumor establishment ( $\geq 100-150 \mathrm{~mm}^{3}$ ) into separate treatment groups ( $\mathrm{n}=5$ mice per group).

For the implantation of IC tumors, anesthetized 4-week-old female NU/NU mice were positioned in a stereotactic frame, and a burr hole was created in the skull using a steel bit at $2 \mathrm{~mm}$ right of the sagittal and $2 \mathrm{~mm}$ anterior to the lambdoid suture. A stereotactic frame was used to guide a Hamilton syringe, and 10,000 cells in $2 \mu \mathrm{L}$ were implanted at $4 \mathrm{~mm}$ depth. After implantation, bone wax was used 
Treatments and group sizes were as follows: $n=12$ for HerDox and Lipodox; $n=14$ for Mock. Treatments were delivered via tail vein at a dose of $0.004 \mathrm{mg} / \mathrm{kg}$ based on doxorubicin content as assessed by spectrophotometry of particles and Lipodox. Tumor growth was monitored via luciferase beginning on day 4 after implantation and randomized before treatments.

Bioluminescence and near-infrared fluorescence acquisition. Luciferase monitoring was performed every four days, beginning on day 4 post-implantation. Mice received $200 \mu \mathrm{L}$ intraperitoneal of $30 \mathrm{mg} / \mathrm{mL}$ D-Luciferin (Caliper) dissolved in PBS 10 minutes before imaging using an in vivo imaging system (IVIS). D-Luciferin was allowed to circulate in the animals for 15 minutes, followed by imaging using a PerkinEImer IVIS Lumina Spectrum. Total Flux (photons/sec) signals were quantified using equally sized regions of interest (ROI) centered around the cranial region in Livinglmage ${ }^{\mathrm{TM}}$ software.

NIR image acquisition was performed on freshly excised organs at indicated time points. Average radiant efficiencies $\left(\left[\mathrm{p} / \mathrm{s} / \mathrm{cm}^{2} / \mathrm{sr}\right] /\left[\mu \mathrm{W} / \mathrm{cm}^{2}\right]\right)$ were quantified using regions of interest (ROI) outlining individual organs in Livinglmage ${ }^{\mathrm{TM}}$ software.

MRI. A 9.4 T MRI (BioSpec 94/20USR, Bruker GmbH) was used for imaging tumor locations and volumes. The tumor perimeters were visually aided by intravenous injections of $7.5 \mu \mathrm{mol}$ gadovist contrast agent. Mice were imaged under inhaled $1.7 \%$ isoflurane anesthetic. Images were collected with an in-plane resolution of $70 \mu \mathrm{m}$ using an acquisition matrix of $256 \times 196$ and zero filling in the phase encoding direction to 256 , using a field of view (FOV) of $1.80 \mathrm{~cm} \times 1.80 \mathrm{~cm}$. Twenty consecutive $0.7-\mathrm{mm}$ slices covered the tumor implanted region. Two averages were collected, with a repetition time of $750 \mathrm{~ms}$ and an echo time of $8.77 \mathrm{~ms}$, for a total scan time of 4.9 minutes using a mouse 4-channel brain array coil (T11071V3, Bruker $\mathrm{GmbH}$ ) for reception and a whole-body transmission coil (T10325V3, Bruker $\mathrm{GmbH}$ ) for excitation. Volume calculations for positive contrast brain regions were determined by integration over the entire tumor by a blinded analyzer. For each slice containing tumor-enhanced regions, an ROI was drawn to encompass the area. The area of each slice was multiplied by the slice thickness, and the individual volumes were summed to determine the area of the tumor. The analysis utilized the Bruker Paravision 5.1 software. MRI core staff performed quantifications in a blinded fashion.

Biodistribution. For the quantification of particle delivery by inductively coupled plasma mass spectrometry (ICP-MS), each mouse was administered a single tail vein injection of HPK bioparticles loaded with gallium(III) metallated corrole (HPK-S2Ga or HerGa) ${ }^{13}$ or S2Ga alone, at $1.5 \mathrm{nmoles} \mathrm{S2Ga}$ per injection. At $6 \mathrm{~h}$ after injection ( $\mathrm{n}=2$ per treatment), mice were euthanized, and the major organs (brain, heart, kidneys, liver, lungs, spleen, and tumors) were excised, weighed, and transferred to the University of California Los Angeles ICP-MS core facility. Samples were digested overnight and processed by ICP-MS to measure the tissue content of $\mathrm{Ga}(\mathrm{III})$ metal. 

bioparticles loaded with NIR Alexa Fluor 680-labeled oligonucleotides at a dose equal to 1.50 nmoles

396 oligonucleotide/injection. Mice were monitored by epifluorescence imaging at the indicated time points 397 after injection using an IVIS® Spectrum (PerkinElmer, Waltham, MA), followed by tissue harvesting and 398 the acquisition of average radiant efficiency $\left(\left[\mathrm{p} / \mathrm{s} / \mathrm{cm}^{2} / \mathrm{sr}\right] /\left[\mu \mathrm{W} / \mathrm{cm}^{2}\right]\right)$ per tissue. Where indicated, the 399 relative tissue content of NIR-ODN was determined based on the extrapolation of measurements 400 acquired from extracted tissue against a standard curve. Tumors were implanted 8 days before mice 401 received systemic NNCs, allowing sufficient time for damaged vessels to repair, and NIR-ODN alone was 402 used to detect the possibility of vascular leakage.

403 Mice ( $n=5$ each treatment) receiving directly labeled protein or particles (NIR-labeled HPK 404 capsomeres, Tz, or BSA) were injected with the indicated treatment through a single tail vein injection at $40512 \mathrm{nmol}$ of labeled protein/injection. Proteins were labeled with Alexa Fluor-680 at primary amines and 406 isolated from the unconjugated dye by size exclusion chromatography using a commercial protein 407 labeling kit, following the manufacturer's protocol (LifeTechnologies).

Statistical methods. Except where indicated, in vitro data are presented as the mean of triplicate samples \pm standard deviation from at least three independent experiments. For normally distributed in 411 vitro data, significant differences were determined by one-way analysis of variance (ANOVA) followed by 412 Tukey's post hoc analysis, unless otherwise indicated. In vivo data are presented as mean \pm standard 413 deviation. Non-parametric analyses were used to determine significant differences within in vivo 414 experiments, where appropriate, using Kruskal-Wallis tests followed by Mann-Whitney post hoc 415 analysis.

416

417 
Bioinformatic and clinical sources support the use of HER3 as a homing beacon for targeting metastatic and TNBC tumors. Invasive breast carcinoma exhibits significantly increased HER3 expression compared with normal breast tissue (Fig. 1A). Additionally, $81 \%$ of cases exhibiting a triplenegative phenotype of below-average estrogen receptor (ER), progesterone receptor (PR), and HER2 expression, showed above-average HER3 expression (Fig. 1B). In agreement, the human TNBC lines BT549 and MDA-MB-231 (MDA-231+) and the mouse TNBC line 4T1 display considerable HER3 on the cell surface (Fig. 1C), unlike the MDA-MB-231 sub-line (MDA-231-), which lacks detectable cell-surface HER3 (Fig. 1, C, D). Patient-derived HER2+ breast tumor cells that escaped HER2-targeted intervention also displayed increased HER3 expression compared with patient-matched normal breast cells (Fig. 1E).

The recombinant protein HPK contains the receptor-binding region of the HER3 ligand neuregulin-1 $\alpha^{11}$ expressed as an $\mathrm{N}$-terminal fusion to a membrane-penetrating moiety derived from the adenovirus penton base capsid protein, which is further modified by a C-terminal decalysine tail (Fig. 1F). The penton base domain of HPK drives the formation of highly stable pentameric barrels, observed as ring-like structures under TEM (Fig. 1G), similar to viral capsomeres. ${ }^{22}$ HER3 specificity and species cross-reactivity were confirmed by human HER3 peptide blockage of capsomere binding to mouse and human HER3-expressing TNBC cell lines (Fig. 1H), consistent with the high amino acid sequence identity between human and mouse HER3 (Fig. 1H, inset). ${ }^{23}$

The protonation of solvent-accessible residues lining the lumen of the HPK capsomere barrel (Supplementary Fig. S1) upon exposure to the reduced endosomal pH may mediate the endosomolytic mechanism. Charge-mediated dispersion was predicted by simulation of HPK pentamers in low $\mathrm{pH}$, which disrupted pentamerization, dispersing the monomers and exposing the intra-pentamerization domains (Fig. 1I, Supplementary Fig. S1 and Supplementary Movie 1). Hydrophobic domain exposure may enable interactions with endosomal membrane lipids, leading to membrane destabilization under acidic $\mathrm{pH}$. Consistent with this finding, the proton pump inhibitor bafilomycin sequestered HPK in vesiclelike structures and prevented HPK diffusion into the cytoplasm of 4T1 TNBC cells, suggesting that endosomal penetration is $\mathrm{pH}$-dependent (Fig. 1J). This finding supports the intracellular trafficking profile of HPK, which undergoes robust uptake coincident with HER3 (Supplementary Fig. S2) and overlaps with early (EEA1) endosomes but not with the lysosomal biomarker Rab7 (Fig. 1K), while distributing to post-endosomal fractions including cytosolic and cytoskeletal compartments (Fig. 1L and 
with HPK, a penton base-deleted construct, $\mathrm{H} \Delta \mathrm{PK}$ (Fig. 1F), displays early sequestration in the membrane compartment and considerably reduced arrival at late (cytoskeletal) trafficking compartments (Fig. 1L and Supplementary Fig. S2), indicating that post-endosomal delivery requires the penton base domain.

Computational modeling shows that the formation of HPK capsomeres aligns the decalysines on one end of the barrel (Supplementary Fig. S1), creating a positively-charged surface that repels the capsomeres from one another in solution (Fig. 2A). The exposure of HPK capsomeres to anionic cargo, such as oligonucleotides (ODN), neutralizes the charged surfaces, allowing the capsomeres to converge around the cargo (Fig. 2A). Functional testing shows that HPK binds to ODN cargo at a nearly 1:1 spontaneous binding ratio in the nanomolar range (Fig. 2B). The shape complementarity of the capsomeres and the interaction between inter-capsomere binding motifs (Supplementary Fig. S3) results in a polyhedral assembly (seen under TEM) containing the encapsulated cargo (Fig. 2A), supporting the observation that HPK increases in hydrodynamic diameter upon exposure to ODN (Fig. 2C and Supplementary Fig. S3) and retains fluorescently-tagged ODN on ultrafiltration membranes (Fig. 2D). The resulting assembly protects nucleic acid cargo from degradation by serum endonucleases as seen by serum-protection assay and gel electrophoresis (Fig. 2E), especially in comparison to enzyme-inactivating conditions such as low temperature $\left(0^{\circ} \mathrm{C}\right)$ and heat invactivation (H.I.). These features taken together distinguish these nano-sized bioparticles as NNCs. The predicted display of HER3 ligands distributed over the particle surface (Fig. 2A) is supported by immunocytofluorescence of patient-derived tumor cells after exposure to NNCs, which shows the accumulation of HPK NNCs at HER3 sites when added to primary breast tumor cells freshly excised from a HER2+ patient (Fig. 2F). Intercalating the ODN with Dox (Supplementary Fig. S3) before assembly with HPK (Supplementary Fig. S3) generates drug-loaded NNCs, designated HerDox, which retain a similar polyhedral shape and size as drug-lacking NNCs (Fig. 2G and Supplementary Fig. S3). The reaction occurs at a 6:1:7 molar stoichiometry of HPK:ODN:Dox in the nanomolar range (Supplementary Fig. S3), with assembled particles showing no detectable drug leakage during ultrafiltration (Fig. $2 \mathbf{H})$. The therapeutic efficacy of HerDox compared favorably against liposomal Dox (Lipodox) for reducing HER3+ TNBC cell growth in culture (Fig. 2I) and reducing peripheral TNBC tumor growth in vivo following systemic delivery (Fig. 2J and Supplementary Fig. S4). Drug-lacking NNCs (empty particles) showed no growth-promoting effect on tumor cells in vitro and in vivo (Fig. 2I, J and Supplementary Fig. S4) and lacked anti-NNC immunogenicity in immunocompetent mice (Supplementary Fig. S4).

\section{Systemic NNCs enter the mouse brain parenchyma}

We systemically administered NNCs carrying NIR-labeled ODN to mice bearing peripheral HER2+/HER3+ JIMT1 tumors to track NNC tissue distribution. NNCs exhibited tumor-preferential 
accumulation and were detected in the brain, in contrast with the negative control molecule, Tz (Fig. 3A), which homes to HER2+ tumors but does not cross the BBB. ${ }^{26,27}$ Similar findings were observed for HPK capsomeres directly labeled with an NIR dye, which could be detected in the brains of tumor-bearing (Fig. 3B) and tumor-free (Supplementary Fig. S5) mice, unlike labeled Tz (Fig. 3A-B and Supplementary Fig. S5) and non-targeted protein (BSA; Supplementary Fig. S5). These findings were validated by ICP-MS of immunocompetent mouse tissue lysates after systemic delivery of HPK bioparticles delivering a metallated probe (gallium[III] corrole or S2Ga) ${ }^{13}$ (Fig. 3C). In contrast with the untargeted probe, HPK-mediated delivery resulted in $\mathrm{Ga}(\mathrm{III})$ accumulation in mouse brain tissue and peripheral syngeneic TNBC tumors (Fig. 3C).

In mice bearing peripheral JIMT1 tumors, systemic NNCs were detected in tumors and brains at 2.5 and $4 \mathrm{~h}$ after administration and remained detectable in tumors but not in brains after $24 \mathrm{~h}$ (Fig. 3D, F). Similarly, systemically administered NIR-labeled HPK capsomeres remained detectable in the brains of tumor-free immunocompetent mice up to $4 \mathrm{~h}$ after administration and were cleared from brains by $24 \mathrm{~h}$ (Supplementary Fig. S5). Immunohistological evaluation of brains collected $2.5 \mathrm{~h}$ after systemic administration showed robust levels of HER3 on the brain vasculature as identified by the tight junction marker claudin-5, and NNCs were detected in both the vasculature $(\mathrm{V})$ and extravascular parenchyma (P) (Fig. 3E, F). To assess whether NNCs retained cargo in the brain vasculature and extravascular parenchyma, we analyzed serial visual planes along the z-axis of independent brain specimens, focusing on the planes transecting the vessel $(V)$ and the parenchyma $(P)$ outside of the vessel (Fig. 3G, schematic and Supplementary Fig. S5). HPK and the fluorescently-tagged cargo (NIR-ODN) coincided both within the vessel (Fig. 3G, graph, "V") and within the parenchyma (Fig. 3G, graph, “P”), whereas non-overlapped NIR-ODN was low to negligible in both locations, suggesting that the cargo remained encapsulated in the bioparticles in both vasculature and parenchyma.

\section{HER3 mediates passage across the human BBB}

Further evaluation of normal brain endothelium showed that HER3 is prominently expressed on healthy adult mouse and human brain vasculature (delineated by claudin 5), whereas HER3 is nearly undetectable in the extravascular brain parenchyma of both species (Fig. 4A, B). Human gene expression analyses show that HER3 compares favorably against conventional BBB transporter genes encoding TfR and GLUT1 for targeting to brain-localized tumors, with significantly reduced HER3 expression on the peripheral endothelia (Fig. 4C) and significantly increased expression on brainmetastatic breast tumors (Fig. 4D). Normal non-CNS tissue also showed significantly lower HER3 expression than TfR and GLUT1 expression (Fig. 4D, E).

To examine whether NNCs carrying NIR-ODN extravasate in human tissue, we used an organon-chip to model the human BBB (BBB chip), which is derived from iPSCs differentiated into apposing 
neuronal and endothelial layers to recapitulate the brain-vascular interface. ${ }^{28}$ Channels creating the closed vessel and overlaying neuronal tissue enable the flow of molecules through the endothelial tube (Fig. 5A), the integrity of which was validated using fluorescently-labeled dextrans of various sizes. ${ }^{28}$ Consistent with the histological findings for both mouse and human endothelia, the human BBB chip displayed considerable HER3 levels on the endothelial surface compared with the neuronal layer (Fig. 5B). HER3 levels were significantly higher on the endothelial surface abutting the neuronal layer compared with that at the distal endothelium (Fig. 5B, C). HPK NNCs flowing through the endothelial tube showed localization at the endothelial-neuronal (proximal) interface coinciding with high HER3 levels compared with the distal endothelial surface (Fig. 5B and D). Approximately $42 \%$ of NNCs injected into the endothelial tube were collected from the neuronal chamber effluent (Fig. 5B and D), suggesting that NNCs successfully crossed the endothelial barrier. Pre-adsorbing the NNCs with a HER3-blocking peptide before injection into the endothelial tube significantly reduced NNC emergence into the neuronal chamber as detected by sandwich ELISA of the neuronal chamber effluent (Fig. 5E) and ICC of neuronal and endothelial chamber surfaces (Fig. 5F), suggesting that BBB transit is mediated by HER3. Free NIRODN was largely retained in the endothelial tube and only NIR-ODN delivered by NNCs was detected by ICC in the neuronal layer (Fig. 5G) consistent with the inability of free nucleic acids to permeate the vasculature and cell membranes, and further confirming the integrity of the endothelial tube.

\section{NNCs accumulate in intracranial tumors after systemic delivery}

\section{Systemic NNCs deliver chemotherapy to intracranial tumors} expressing intracranial (IC) tumors. To test this, we systemically administered NNCs carrying NIR-ODN (HPK-NIR-ODN) by single tail vein injection in mice bearing IC 4T1 TNBC tumors tagged with luciferase and GFP (4T1lucGFP) (Fig. 6A). Immunohistofluorescence of brain sections collected at $4 \mathrm{~h}$ after injection shows that NNCs coincided with IC tumors and caveolin-positive sites along the brain-tumor vasculature, suggesting that extravasation may occur by caveolae-mediated transit (Fig. 6B). Systemic NNCs showed preferential accumulation in IC tumors in comparison to non-tumor tissue (liver, spleen, heart, and lung; Fig. 6C) and non-tumor brain areas (Supplementary Fig. S6). Moreover, systemic HPK-NIR-ODN preferentially accumulated at IC tumors compared with free NIR-ODN, which was either undetectable or showed no coincident localization with tumors (Fig. 6D and Supplementary Fig. S6). Closer histological examination confirmed that free NIR-ODN was restricted to the vasculature in both tumor and non-tumor areas, whereas HPK-NIR-ODN showed considerable extravascular spread throughout the tumor tissue (Fig. 6D and Supplementary Fig. S6) 
These findings support a mechanism whereby systemic NNCs can cross the BBB using a HER3mediated route associated with caveolae and accumulate in IC TNBC tumors using HER3 entry and subsequent $\mathrm{pH}$-mediated membrane disruption (Supplementary Fig. S7). To examine the therapeutic efficacy of NNCs, we compared HerDox against the FDA-approved Lipodox in mice bearing IC 4T1lucGFP tumors and monitored tumor growth by bioluminescence imaging (BLI) and magnetic resonance imaging (MRI) (Supplementary Fig. S8). Stratification of the outcomes based on rates of increase in brain bioluminescence revealed three phenotypes that distinguished HerDox from Lipodox treatments. The first was characterized by a sudden exponential increase in bioluminescence once tumors exceeded $10^{8}$ relative luminescence units (RLU), which was accompanied by a concomitant decline in health and was observed in 43\% (6/14) of Mock- and 33\% (4/12) of Lipodox-treated animals but only 1 (8\%) of 12 HerDox-treated animals 15 days after tumor implantation (Fig. 6E). The remaining mice in each cohort displayed the second phenotype, characterized by luminescence maintained below $10^{8} \mathrm{RLU}$, observed in $92 \%$ of the HerDox cohort compared with $57 \%$ of the Mock and $67 \%$ of the Lipodox cohorts (Fig. 6E). A subset of this second phenotype was characterized by negligible tumor growth, observed in $42 \%$ of both the HerDox and Lipodox cohorts but only $7 \%$ of the Mock cohort (Fig. 6E). HerDox significantly reduced overall tumor growth rates as measured by BLI relative to Mocktreated mice, whereas Lipodox produced a broad range of effect entailing no significant difference compared with the other treatments (Supplementary Fig. S8). Tumor imaging in live mice reflected the quantified growth rates, with tumor volume differences becoming more apparent 11 days after implantation (Fig. 6F). MRI performed on day 11 captured tumor volumes mid-study and showed that HerDox yielded significantly reduced tumor sizes compared with the Mock treatment (Fig. 6F and Supplementary Fig. S8). Although the Lipodox-treated cohort showed no significant differences in MRIdetected tumor volumes compared with either the Mock- or HerDox-treated cohorts at this time point (Supplementary Fig. S8), representative members of the Lipodox-treated group showed worsened health deterioration, including extracranial metastases and reduced ambulatory ability, whereas such characteristics were not detected in the HerDox-treated mice at this time point (Supplementary Fig. S9 and Supplementary Movies 2-3). These observations compelled us to sacrifice a representative group of mice from each cohort on day 15 (after the final BLI) to perform comparative tissue and blood analyses while continuing to monitor the remaining mice to assess whether differences between the cohorts continued to be displayed. Differences in mouse health and mobility were reflected by the considerably higher proportions of Lipodox- (5/7) and Mock-treated (10/10) mice that required early euthanasia due to $\mathrm{BCS}<2^{20,21,29}$ (Supplementary Table 1) compared with the number of HerDoxtreated (3/7) mice, despite similar declines in weight among all cohorts (Supplementary Fig. S9). 
598 cohorts (Supplementary Table 2), a higher percentage of HerDox-treated mice (4/7) avoided early 599 euthanasia compared with Lipodox- (2/7) and Mock-treated (0/10) mice (Supplementary Fig. S9).

$600 \quad$ Harvested brains from Lipodox-treated mice showed significantly increased damage to non-tumor 601 brain areas compared with those from HerDox-treated mice, based on measuring apoptotic cell death in 602 the same brain regions (TUNEL stain; Fig. 6G). A comparison of tumor vs. non-tumor areas showed that 603 HerDox yielded significantly higher TUNEL-positive tumor cells compared to non-tumor cells in the 604 contralateral brain region. Additionally, HerDox-treated tumors showed significantly higher TUNEL605 positivity than Lipodox-treated tumors. In contrast, Lipodox elicited significantly increased TUNEL606 positivity in non-tumor areas compared with HerDox-treatment. These collective findings suggest that 607 HerDox retains the tumoricidal activity of Dox while improving targeted toxicity to brain-localized tumors 608 and preserving healthy brain tissue compared with Lipodox.

609

610

611 
We have demonstrated that systemically administered NNC bioparticles can cross the BBB and accumulate in IC TNBC tumors in mice through HER3-mediated mechanisms. Systemic administration of NNCs containing intercalated Dox reduced IC TNBC tumor growth in mice with low to negligible apoptotic effects on normal brain tissue, in contrast to the current clinically available treatment, Lipodox. We showed that HER3 is prominently expressed on both healthy adult mouse and human brain endothelium, with low to negligible expression in the brain parenchyma of both species. Using a human iPSC-derived BBB chip, we showed that NNCs recognized HER3 on the human blood vessel wall and crossed the human BBB using HER3-mediated transport.

This study illustrates that HER3 can be used as a new and singular route for ligand-directed nano-carrier transfer across the BBB and into IC tumors. Increasing evidence supports an association between HER3, brain metastases, and brain-localized tumors. ${ }^{7,30-32}$ Although the ErbB gene family is associated with neural growth and development, ${ }^{10}$ the presence of ErbB family members on the BBB has received less attention. Kastin et al. (2004) used radiolabeled neuregulin-1- $\beta 1$ to show that blockade of HER3 and HER4 but not HER2 prevented the entry of systemic neuregulins into the brain parenchyma, ${ }^{33}$ suggesting that HER3 normally functions in the brain endothelium to transcytose neuregulins from the circulatory system. In contrast, HER2 does not transcytose across the blood vessel wall ${ }^{34,35}$ despite its expression on the brain endothelium, ${ }^{36}$ which may explain the inability of HER2 antibodies to breach the BBB. Therefore, the presence of a receptor on the BBB does not necessarily ensure trans-endothelial passage of anti-receptor antibodies, highlighting the utility of ligand-mimicking molecules such as HPK for overcoming such limitations. HPK has advantages over molecules that target traditionally accepted BBB receptors, such as TfR and GLUT1. Bioinformatics analyses here suggest that HER3 is expressed at significantly higher levels on brain metastatic breast tumors compared with TfR and GLUT1, with significantly lower expression in normal peripheral tissue, including non-CNS endothelia, augmenting the potential efficacy of HER3-homing nano-carriers targeting IC tumors.

Systemic nanomedicines can gain better access to extravascular and tumor environments by employing naturally occurring transcellular routes associated with endothelial biomarkers. ${ }^{37}$ Likewise, HPK utility is based on the premise that circulating neuregulins require transport across the endothelium through a non-degradative transcellular pathway to allow for undigested release into the brain parenchyma. Transcytosis across the endothelium is typically mediated through caveolae trafficking, ${ }^{38}$ which is distinct from classical clathrin-mediated endocytosis that sorts vesicles to a lysosomal degradation pathway after transitioning through vesicle acidification. ${ }^{39}$ Our data showed that caveolin coincides with vascular-associated NNCs in the brain that later emerge with cargo into the parenchyma, supporting the unperturbed passage of NNCs across the BBB. HER3 undergoes a dramatic 
HPK particles co-route HER3 into tumor cells coincident with particle uptake and trafficking that occurs within minutes after cell binding. Not only does this activity support a rapid and robust system of cell uptake but may contribute to therapeutic effect by sequestering and downregulating HER3 through particle multivalency. This may explain why HPK particles without packaged drugs show no growthstimulating effects while in some circumstances reduce HER3 activation by wild-type neuregulins ${ }^{13}$ and partially reduce tumor growth.

These studies continue our ongoing interrogation of the elusive mechanisms underlying the endosomolytic functions of the penton base capsomere and its derivative proteins, such as HPK. We have shown that the solvent-accessible pore comprising the capsomere barrel is lined with histidines and charged residues, the protonation of which causes the repellence of HPK monomers, exposing the hydrophobic domains that mediate pentamerization. ${ }^{41}$ Similar principles have been demonstrated for synthetic nanostructures undergoing $\mathrm{pH}$-triggered supramolecular assembly/disassembly. ${ }^{42} \mathrm{Here}$, we show that HPK monomers extend away from the capsomere axis under increasingly acidifying conditions using MD simulation, supporting our earlier functional studies showing that capsomeres reduce to smaller constituents under decreasing $\mathrm{pH}$ conditions. ${ }^{12}$ We also showed that HPK avoids distribution to Rab7+ endolysosomes and enters the cytoskeletal compartment, whereas ligands lacking the penton base domain remain associated with the membrane compartment after uptake. Cytoskeletal attachment facilitates the post-endosomal trafficking of adenovirus ${ }^{43,44}$ and capsid proteins ${ }^{25,45}$ within the cell. We propose that the exposure of hydrophobic pentamerization domains under low $\mathrm{pH}$ conditions disrupt vesicle lipids, weakening the endosome wall. In support we show that inhibiting vesicle acidification retained HPK capsomeres in vesicle-like puncta, reducing their diffusion into the extravesicular space. The naturally evolved structure afforded by the penton base domain provides a potentially modulatable function enabling low $\mathrm{pH}$-mediated penetration into tumor cells and avoiding premature release in the endothelium, as demonstrated in this study.

The use of a human iPSC-derived BBB chip validated our findings in mice, showing that HER3 is prominently expressed on the human BBB in contrast to non-BBB endothelia and extravascular brain parenchyma and that NNCs use HER3 to extravasate the brain vasculature. The cross-reactivity of NNCs to both mouse and human HER3 enables preclinical translational value to be drawn from both human tissue and in vivo mouse studies. Specifically, we used in vivo and in situ detection to examine brain extravasation in mice and supplemented these findings with studies using human BBB chips to validate our BBB extravasation findings in a dynamic model and test this process in a human system. The benefit of species cross-reactivity further supported our therapeutic efficacy studies, in which HerDox NNCs were benchmarked against Lipodox in a syngeneic 4T1 model mimicking late-stage TNBC. Immunodeficient mice lacking spontaneous rejection of IC tumors provided a background against which HerDox performance could be assessed. Our supplementary findings show that immunocompetent tumor-free mice receiving therapeutically-equivalent dosages of NNCs lacked anti- 
NNC immune response in contrast to Ad5 used as a control antigen. Recent human trials of oncolytic adenoviruses for glioblastoma support the safety of whole viruses in the brain, ${ }^{46}$ and support our findings that show no detectable apoptotic marker induction in non-tumor regions after systemic delivery of HPK bioparticles in contrast to non-targeted chemotherapy.

In conclusion, these studies demonstrate that HER3 is expressed on the BBB and mediates the extravasation and tumor-targeting of systemic ligand-mimicking bioparticles for reducing IC TNBC growth. A growing range of tumor types are characterized by HER3-associated resistance, metastasis, and brain-invasion. These studies pave the way toward developing HER3 bioparticles capable of targeting various brain-localized tumors.

\section{ACKNOWLEDGMENTS}

The authors thank the Cedars-Sinai Research Imaging core for animal imaging; the Electron Imaging Center for NanoMachines (EICN) at UCLA for EM services; the ICP-MS core at UCLA for quantification of metal content in tissues; Zeev Gross, PhD, and Harry Gray, PhD, for the use of galliummetallated corroles in the biodistribution study using ICP-MS; Omar Haffar and Kent Iverson for critical review and intellectual feedback; Shana Svendsen, $\mathrm{PhD}$ for editing; and BioScience Writers for editorial assistance. LMK thanks C Rey and AACM Kauwe for ongoing support.

\section{FUNDING}

This research was supported by grants from the National Institutes of Health (NIH) [NCl R01 CA129822, R01 CA140995, and NCATS UL1 TR001881]; and the Department of Defense (DoD) [BCRP W81XWH-15-1-0604, W81XWH1910592]. F.A.V. was supported in part by a training grant from the National Institutes of Health [T32 HL134637]. B.O. and S.S. were supported by National Institutes of Health (NIH) UG3NS105703.

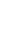


716 1. Arvanitis, C. D.; Ferraro, G. B.; Jain, R. K., The blood-brain barrier and blood-tumour barrier in 717 brain tumours and metastases. Nature Reviews Cancer 2020, 20 (1), 26-41.

718 2. Persaud-Sharma, D.; Burns, J.; Trangle, J.; Moulik, S., Disparities in Brain Cancer in the United

719 States: A Literature Review of Gliomas. Medical Sciences 2017, 5 (3), 16.

$720 \quad 3 . \quad$ Cavaco, M.; Gaspar, D.; Arb Castanho, M.; Neves, V., Antibodies for the Treatment of Brain 721 Metastases, a Dream or a Reality? Pharmaceutics 2020, 12 (1), 62.

722 4. Foulkes, W. D.; Smith, I. E.; Reis-Filho, J. S., Triple-negative breast cancer. The New England 723 journal of medicine 2010, 363 (20), 1938-48.

724 5. Mishra, R.; Patel, H.; Alanazi, S.; Yuan, L.; Garrett, J. T., HER3 signaling and targeted therapy 725 in cancer. Oncology reviews 2018, 12 (1), 355.

$726 \quad 6 . \quad$ Kabraji, S.; Ni, J.; Lin, N. U.; Xie, S.; Winer, E. P.; Zhao, J. J., Drug Resistance in HER2727 Positive Breast Cancer Brain Metastases: Blame the Barrier or the Brain? Clinical Cancer Research 7282018.

729 7. Da Silva, L.; Simpson, P. T.; Smart, C. E.; Cocciardi, S.; Waddell, N.; Lane, A.; Morrison, B. 730 J.; Vargas, A. C.; Healey, S.; Beesley, J.; Pakkiri, P.; Parry, S.; Kurniawan, N.; Reid, L.; Keith, P.; 731 Faria, P.; Pereira, E.; Skalova, A.; Bilous, M.; Balleine, R. L.; Do, H.; Dobrovic, A.; Fox, S.; Franco, M.; Reynolds, B.; Khanna, K. K.; Cummings, M.; Chenevix-Trench, G.; Lakhani, S. R., HER3 and downstream pathways are involved in colonization of brain metastases from breast cancer. Breast Cancer Res 2010, 12 (4), R46.

8. Lee, Y.; Ma, J.; Lyu, H.; Huang, J.; Kim, A.; Liu, B., Role of erbB3 receptors in cancer therapeutic resistance. Acta Biochimica et Biophysica Sinica 2014, 46 (3), 190-198.

9. Liu, X.; Liu, S.; Lyu, H.; Riker, A. I.; Zhang, Y.; Liu, B., Development of Effective Therapeutics Targeting HER3 for Cancer Treatment. Biological Procedures Online 2019, 21 (1), 5.

10. Kataria, H.; Alizadeh, A.; Karimi-Abdolrezaee, S., Neuregulin-1/ErbB network: An emerging modulator of nervous system injury and repair. Prog Neurobiol 2019, 180, 101643.

11. Han, X.; Kasahara, N.; Kan, Y. W., Ligand-directed retroviral targeting of human breast cancer cells. Proceedings of the National Academy of Sciences of the United States of America 1995, 92 (21), 9747-51.

12. Alonso-Valenteen, F.; Pacheco, S.; Srinivas, D.; Rentsendorj, A.; Chu, D.; Lubow, J.; Sims, J.; Miao, T.; Mikhael, S.; Hwang, J. Y.; Abrol, R.; Medina Kauwe, L. K., HER3-targeted protein chimera forms endosomolytic capsomeres and self-assembles into stealth nucleocapsids for systemic tumor homing of RNA interference in vivo. Nucleic acids research 2019, 47 (21), 11020-11043. 13. Sims, J. D.; Taguiam, J. M.; Alonso-Valenteen, F.; Markman, J.; Agadjanian, H.; Chu, D.; Lubow, J.; Abrol, R.; Srinivas, D.; Jain, A.; Han, B.; Qu, Y.; Mirzadehgan, P.; Hwang, J.-Y.; 
Rentsendorj, A.; Chung, A.; Lester, J.; Karlan, B. Y.; Gray, H. B.; Gross, Z.; Giuliano, A.; Cui, X.; Medina-Kauwe, L. K., Resistance to receptor-blocking therapies primes tumors as targets for HER3homing nanobiologics. Journal of Controlled Release 2018, 271, 127-138. 14. Baker, N. A.; Sept, D.; Joseph, S.; Holst, M. J.; McCammon, J. A., Electrostatics of nanosystems: application to microtubules and the ribosome. Proc Natl Acad Sci U S A 2001, 98 (18), 10037-41.

15. Dolinsky, T. J.; Nielsen, J. E.; McCammon, J. A.; Baker, N. A., PDB2PQR: an automated pipeline for the setup of Poisson-Boltzmann electrostatics calculations. Nucleic acids research 2004, 32 (Web Server issue), W665-7.

16. Maier, J. A.; Martinez, C.; Kasavajhala, K.; Wickstrom, L.; Hauser, K. E.; Simmerling, C., ff14SB: Improving the Accuracy of Protein Side Chain and Backbone Parameters from ff99SB. J Chem Theory Comput 2015, 11 (8), 3696-713.

17. Case, D. A.; Cheatham, T. E., 3rd; Darden, T.; Gohlke, H.; Luo, R.; Merz, K. M., Jr.; Onufriev, A.; Simmerling, C.; Wang, B.; Woods, R. J., The Amber biomolecular simulation programs. J Comput Chem 2005, 26 (16), 1668-88.

18. Jain, A.; Barrile, R.; van der Meer, A. D.; Mammoto, A.; Mammoto, T.; De Ceunynck, K.; Aisiku, O.; Otieno, M. A.; Louden, C. S.; Hamilton, G. A.; Flaumenhaft, R.; Ingber, D. E., Primary Human Lung Alveolus-on-a-chip Model of Intravascular Thrombosis for Assessment of Therapeutics. Clin Pharmacol Ther 2018, 103 (2), 332-340.

19. Ebert, A. D.; Shelley, B. C.; Hurley, A. M.; Onorati, M.; Castiglioni, V.; Patitucci, T. N.; Svendsen, S. P.; Mattis, V. B.; McGivern, J. V.; Schwab, A. J.; Sareen, D.; Kim, H. W.; Cattaneo, E.; Svendsen, C. N., EZ spheres: a stable and expandable culture system for the generation of pre-rosette multipotent stem cells from human ESCs and iPSCs. Stem Cell Res 2013, 10 (3), 417-427.

773 20. Foltz, C.; Ullman-Cullere, M., Guidelines for Assessing the Health and Condition of Mice. Laboratory Animal Science 1999, 28. 21. Ullman-Culleré, M. H.; Foltz, C. J., Body condition scoring: a rapid and accurate method for assessing health status in mice. Lab Anim Sci 1999, 49 (3), 319-23.

22. Russell, W. C., Adenoviruses: update on structure and function. J Gen Virol 2009, 90 (Pt 1), 1-20. Binding Site in HER3 Extracellular Domain. Journal of Biological Chemistry 2001, 276 (47), 4426644274.

24. Hong, S. S.; Gay, B.; Karayan, L.; Dabauvalle, M. C.; Boulanger, P., Cellular uptake and nuclear delivery of recombinant adenovirus penton base. Virology. 1999, 262 (1), 163-77. 
26. Azim, H. A.; Azim, H. A., Jr., Systemic treatment of brain metastases in HER2-positive breast cancer: current status and future directions. Future Oncol 2012, 8 (2), 135-44. 27. Okines, A.; Irfan, T.; Khabra, K.; Smith, I.; O'Brien, M.; Parton, M.; Noble, J.; Stanway, S.; Somaiah, N.; Ring, A.; Johnston, S.; Turner, N., Development and responses of brain metastases during treatment with trastuzumab emtansine (T-DM1) for HER2 positive advanced breast cancer: A single institution experience. Breast J 2018, 24 (3), 253-259. 28. Sances, S.; Ho, R.; Vatine, G.; West, D.; Laperle, A.; Meyer, A.; Godoy, M.; Kay, P. S.; Mandefro, B.; Hatata, S.; Hinojosa, C.; Wen, N.; Sareen, D.; Hamilton, G. A.; Svendsen, C. N., Human iPSC-Derived Endothelial Cells and Microengineered Organ-Chip Enhance Neuronal Development. Stem cell reports 2018, 10 (4), 1222-1236.

29. Hickman, D. L. Use of body condition scoring as an endpoint for tumor growth studies; January 31, 2006, 2006. 30. Park, Y. H.; Jung, H. A.; Choi, M. K.; Chang, W.; Choi, Y. L.; Do, I. g.; Ahn, J. S.; Im, Y. H., Role of HER3 expression and PTEN loss in patients with HER2-overexpressing metastatic breast cancer (MBC) who received taxane plus trastuzumab treatment. Br J Cancer 2014, 110 (2), 384-391.

800 31. Tiwary, S.; Preziosi, M.; Rothberg, P. G.; Zeitouni, N.; Corson, N.; Xu, L., ERBB3 is required 801 for metastasis formation of melanoma cells. Oncogenesis 2014, 3, e110.

802 32. Kodack, D. P.; Askoxylakis, V.; Ferraro, G. B.; Sheng, Q.; Badeaux, M.; Goel, S.; Qi, X.; 803 Shankaraiah, R.; Cao, Z. A.; Ramjiawan, R. R.; Bezwada, D.; Patel, B.; Song, Y.; Costa, C.; 804 Naxerova, K.; Wong, C. S. F.; Kloepper, J.; Das, R.; Tam, A.; Tanboon, J.; Duda, D. G.; Miller, C. R.; 805 Siegel, M. B.; Anders, C. K.; Sanders, M.; Estrada, M. V.; Schlegel, R.; Arteaga, C. L.; Brachtel, E.; 806 Huang, A.; Fukumura, D.; Engelman, J. A.; Jain, R. K., The brain microenvironment mediates 807 resistance in luminal breast cancer to PI3K inhibition through HER3 activation. Sci Transl Med 2017, 9 808 (391).

809 33. Kastin, A. J.; Akerstrom, V.; Pan, W., Neuregulin-1-beta1 enters brain and spinal cord by 810 receptor-mediated transport. J Neurochem 2004, 88 (4), 965-70.

811 34. Bertelsen, V.; Stang, E., The Mysterious Ways of ErbB2/HER2 Trafficking. Membranes 2014, 4 812 (3), 424-46.

813 35. Gril, B.; Palmieri, D.; Bronder, J. L.; Herring, J. M.; Vega-Valle, E.; Feigenbaum, L.; Liewehr, 814 D. J.; Steinberg, S. M.; Merino, M. J.; Rubin, S. D.; Steeg, P. S., Effect of Lapatinib on the Outgrowth of 815 Metastatic Breast Cancer Cells to the Brain. Journal of the National Cancer Institute 2008, 100 (15), $816 \quad 1092-1103$.

817 36. Lok, J.; Sardi, S. P.; Guo, S.; Besancon, E.; Ha, D. M.; Rosell, A.; Kim, W. J.; Corfas, G.; Lo, 818 E. H., Neuregulin-1 signaling in brain endothelial cells. Journal of cerebral blood flow and metabolism : 819 official journal of the International Society of Cerebral Blood Flow and Metabolism 2009, 29 (1), 39-43. 
37. Huai, Y.; Hossen, M. N.; Wilhelm, S.; Bhattacharya, R.; Mukherjee, P., Nanoparticle Interactions with the Tumor Microenvironment. Bioconjugate Chemistry 2019, 30 (9), 2247-2263.

822 38. Yuan, S.; Rigor, R., Chapter 4, The Endothelial Barrier. In Regulation of Endothelial Barrier 823 Function, Granger, D. N. G. a. J., Ed. Morgan \& Claypool Life Sciences: San Rafael, CA, 2010.

824 39. Kaksonen, M.; Roux, A., Mechanisms of clathrin-mediated endocytosis. Nature Reviews 825 Molecular Cell Biology 2018, 19, 313.

826 40. Burgess, A. W.; Cho, H.-S.; Eigenbrot, C.; Ferguson, K. M.; Garrett, T. P. J.; Leahy, D. J.; 827 Lemmon, M. A.; Sliwkowski, M. X.; Ward, C. W.; Yokoyama, S., An Open-and-Shut Case? Recent 828 Insights into the Activation of EGF/ErbB Receptors. Molecular Cell 2003, 12 (3), 541-552.

829 41. Fuschiotti, P.; Schoehn, G.; Fender, P.; Fabry, C. M.; Hewat, E. A.; Chroboczek, J.; Ruigrok, 830 R. W.; Conway, J. F., Structure of the dodecahedral penton particle from human adenovirus type 3. J Mol 831 Biol 2006, 356 (2), 510-20.

832 42. Li, Y.; Zhao, T.; Wang, C.; Lin, Z.; Huang, G.; Sumer, B. D.; Gao, J., Molecular basis of 833 cooperativity in pH-triggered supramolecular self-assembly. Nat Commun 2016, 7, 13214.

834 43. Leopold, P. L.; Crystal, R. G., Intracellular trafficking of adenovirus: many means to many ends. 835 Adv Drug Deliv Rev 2007, 59 (8), 810-21.

836 44. Kelkar, S.; De, B. P.; Gao, G.; Wilson, J. M.; Crystal, R. G.; Leopold, P. L., A common 837 mechanism for cytoplasmic dynein-dependent microtubule binding shared among adeno-associated 838 virus and adenovirus serotypes. J Virol. 2006, 80 (15), 7781-5.

839 45. Medina-Kauwe, L. K., Development of adenovirus capsid proteins for targeted therapeutic 840 delivery. Therapeutic delivery 2013, 4 (2), 267-277.

841 46. Fares, J.; Ahmed, A. U.; Ulasov, I. V.; Sonabend, A. M.; Miska, J.; Lee-Chang, C.; 842 Balyasnikova, I. V.; Chandler, J. P.; Portnow, J.; Tate, M. C.; Kumthekar, P.; Lukas, R. V.; Grimm, S. 843 A.; Adams, A. K.; Hébert, C. D.; Strong, T. V.; Amidei, C.; Arrieta, V. A.; Zannikou, M.; Horbinski, C.; 844 Zhang, H.; Burdett, K. B.; Curiel, D. T.; Sachdev, S.; Aboody, K. S.; Stupp, R.; Lesniak, M. S., Neural 845 846 stem cell delivery of an oncolytic adenovirus in newly diagnosed malignant glioma: a first-in-human, phase 1, dose-escalation trial. The Lancet Oncology 2021, 22 (8), 1103-1114. 
847 Figure 1. HER3 expression and HPK penetration of tumor cells.
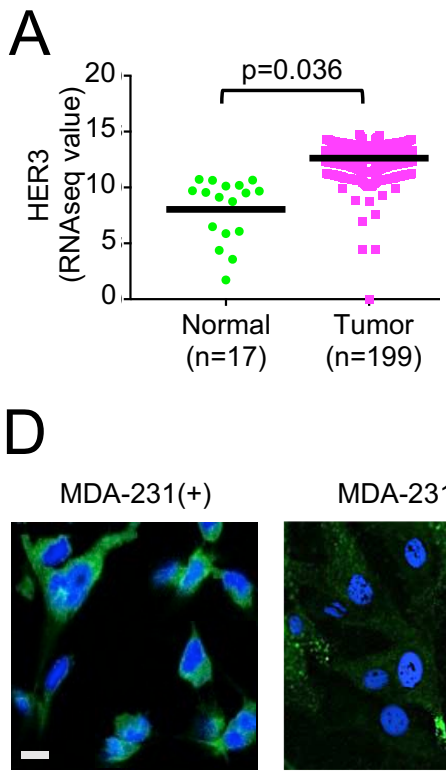

HER3, DAPI
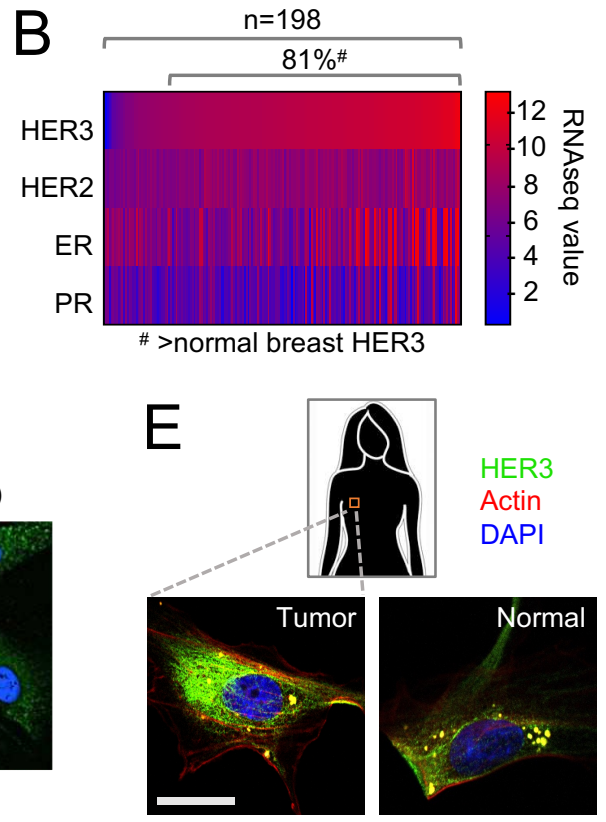
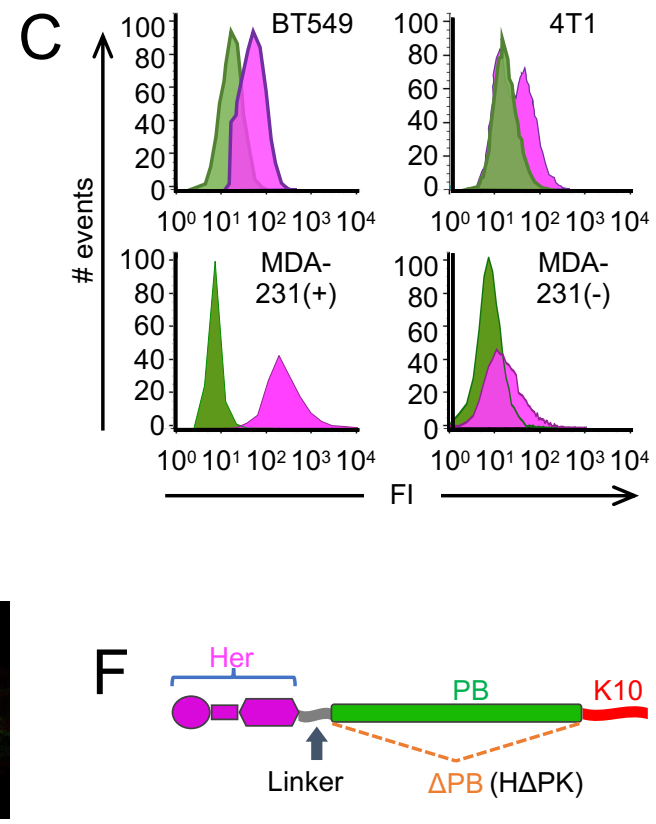

G

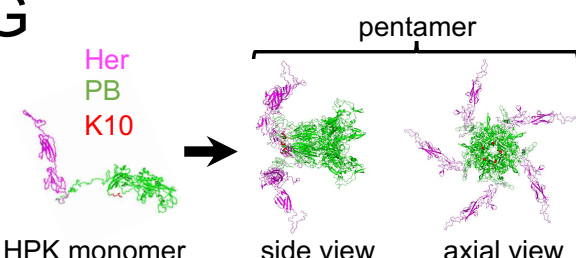

HPK monomer

side view
MDA-231(-)

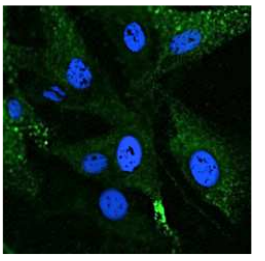

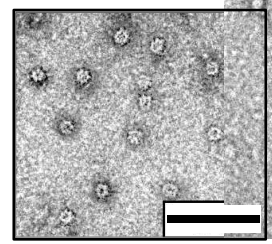

$\mathrm{H}$

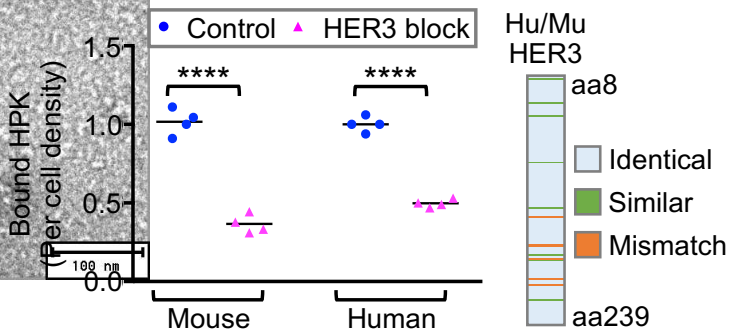

I

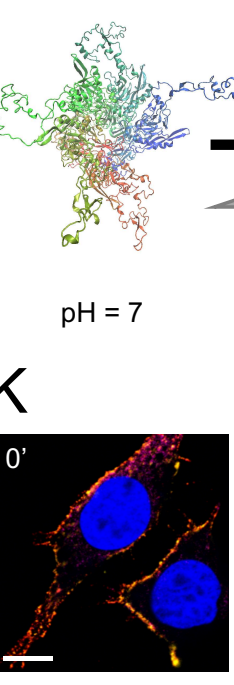

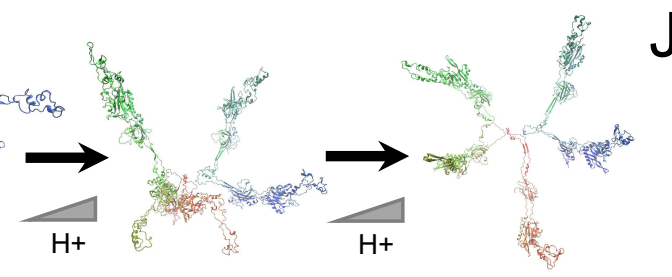

$\mathrm{pH}=3$

$\mathrm{pH}=1$
$\mathrm{F}$

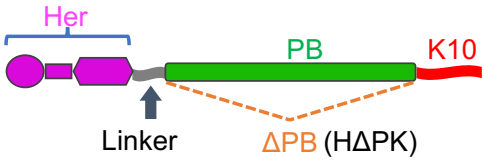

(-) Baf

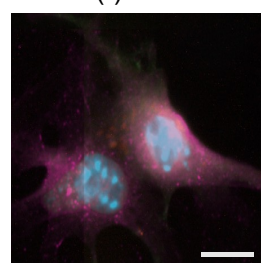

(+) Baf

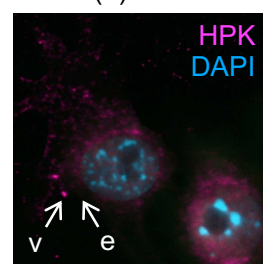

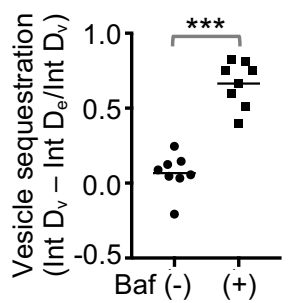

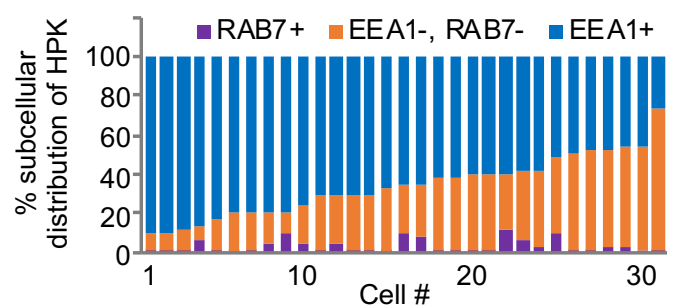


Figure 1. HER3 expression and HPK penetration of tumor cells. A, HER3 gene expression

849 comparing invasive breast cancers and normal breast tissue. B, Gene expression heatmap of TNBC

850 tumors ranked by HER3 expression levels delineating \% above normal breast HER3. C, Flow cytometry

851 of TNBC cell lines based on cell surface HER3. D, Immunocytofluorescence of HER3+ [MDA-231(+)] and 852 no/low HER3-expressing [MDA-231(-)] TNBC cells. Scale bar, $8 \mu \mathrm{m}$. E, Immunocytofluorescence of cells 853 from cancerous and normal breast obtained from the same patient. Scale bar $8 \mu \mathrm{m}$. F, HPK domain map 854 highlighting: HER3-binding motif (Her), flexible linker (Gly-Gly-Ser)2, penton base (PB), decalysine (K10). 855 N, amino-terminus; C, carboxy-terminus. G, Ribbon models of MD-simulated monomeric and pentameric 856 HPK. Designated colors delineate each functional region. Inset, TEM of HPK capsomeres. Scale bar, $857100 \mathrm{~nm}$. H, Cell surface ELISA of HPK binding to human (BT549) and mouse (4T1) TNBC cells -/+ 858 competing HER3 peptide. ${ }^{* * *} p<0.0001(n=4)$. Inset, graphical alignment of mouse and human HER3 859 ligand-binding domains. I, Snapshots of MD-simulated tHPK pentamer for three $\mathrm{pH}$ values. Designated 860 colors distinguish each monomer. J, Immunocytofluorescence of 4T1 cells at 30 min capsomere uptake $861-/+$ bafilomycin-A1. Scale bar $8 \mu \mathrm{m}$. Graph, vesicular (v) and extravesicular (e) intensities. ${ }^{* * *} p<0.001$ 862 ( $n=8) . K$, Capsomere trafficking (immunocytofluorescence) and intracellular distribution (graph) of HPK in 863 HER3+ MDA-MB-435 cells relative to early (EEA1) and late (RAB7) endo/lysosomes. Scale bar, $5 \mu \mathrm{m}$. L, 864 Immunoblots of HER3+ MDA-MB-435 subcellular fractions during HPK or HAPK uptake. Quantified 865 uptake levels were normalized against respective loading controls for cytosolic (GAPDH) and 866 cytoskeletal ( $\beta$-actin) fractions. Fold change is relative to $0 \mathrm{~min}$. 
Figure 2. Formation of HER3-targeting nano-nucleocapsids (NNCs).

A

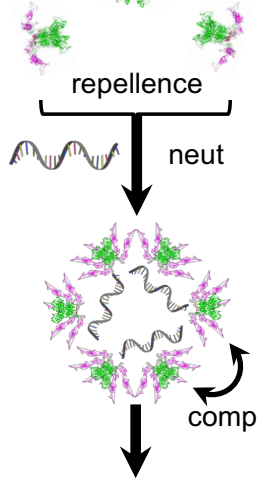

Nano-nucleocapsid (NNC)

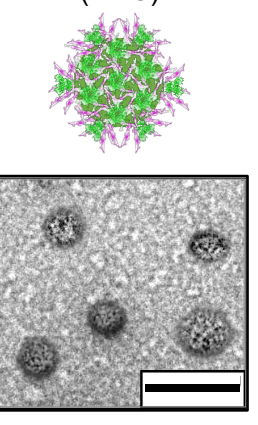

B

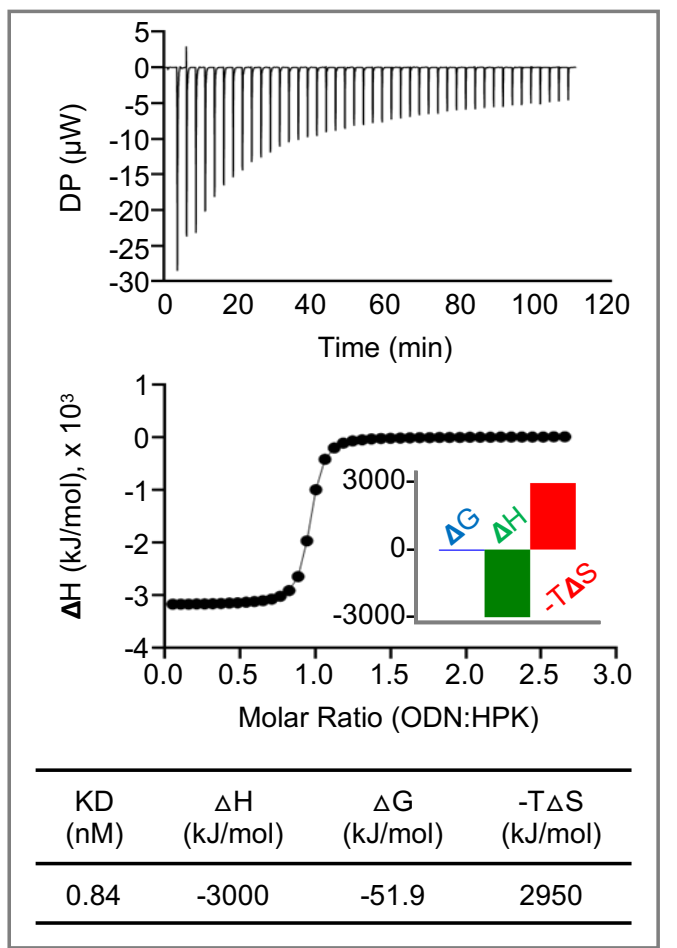

C

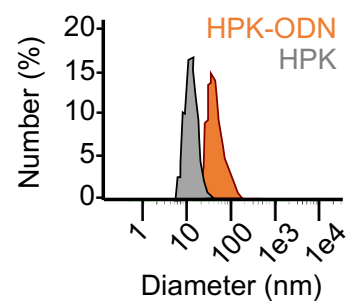

D

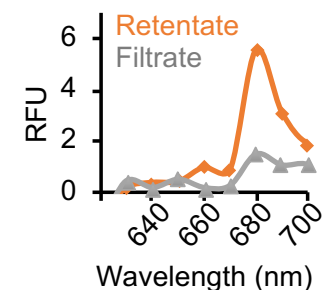

E

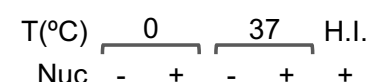

$(-)$

and

(+)

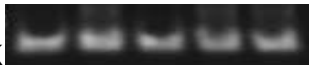

F

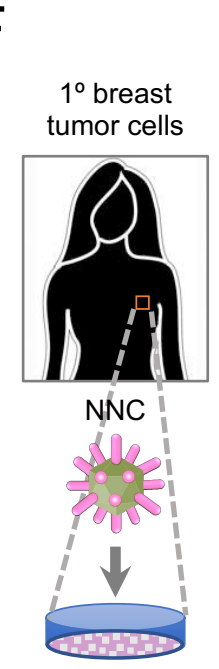

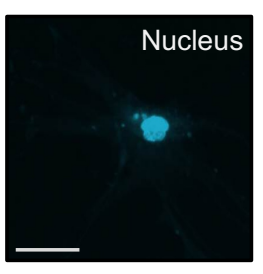
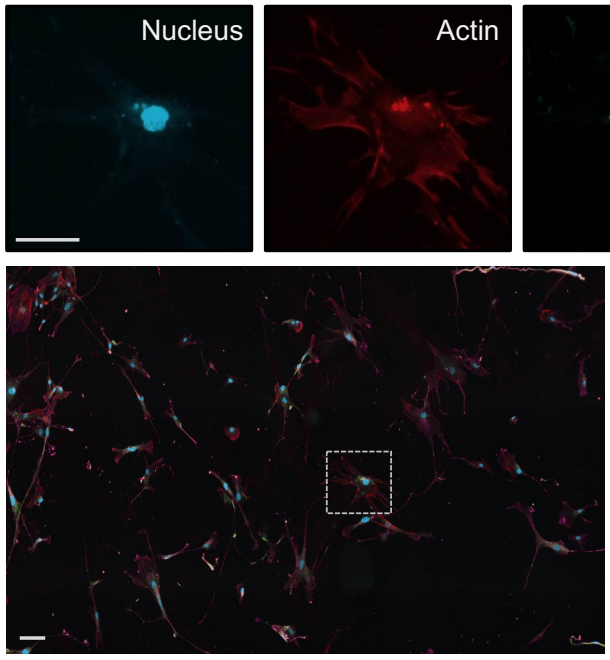
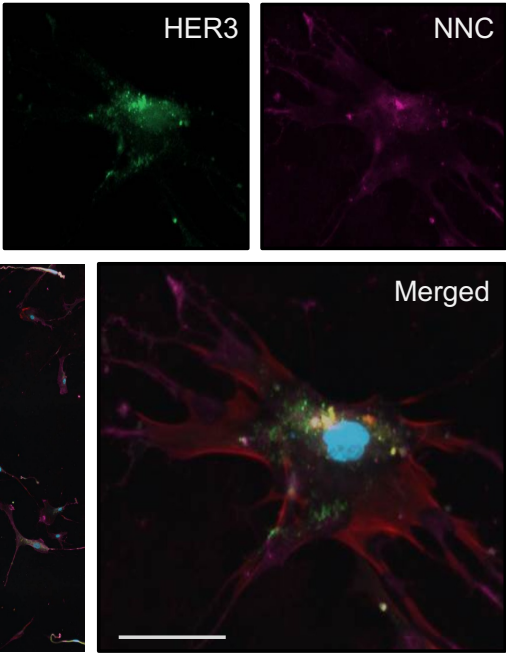

Merged
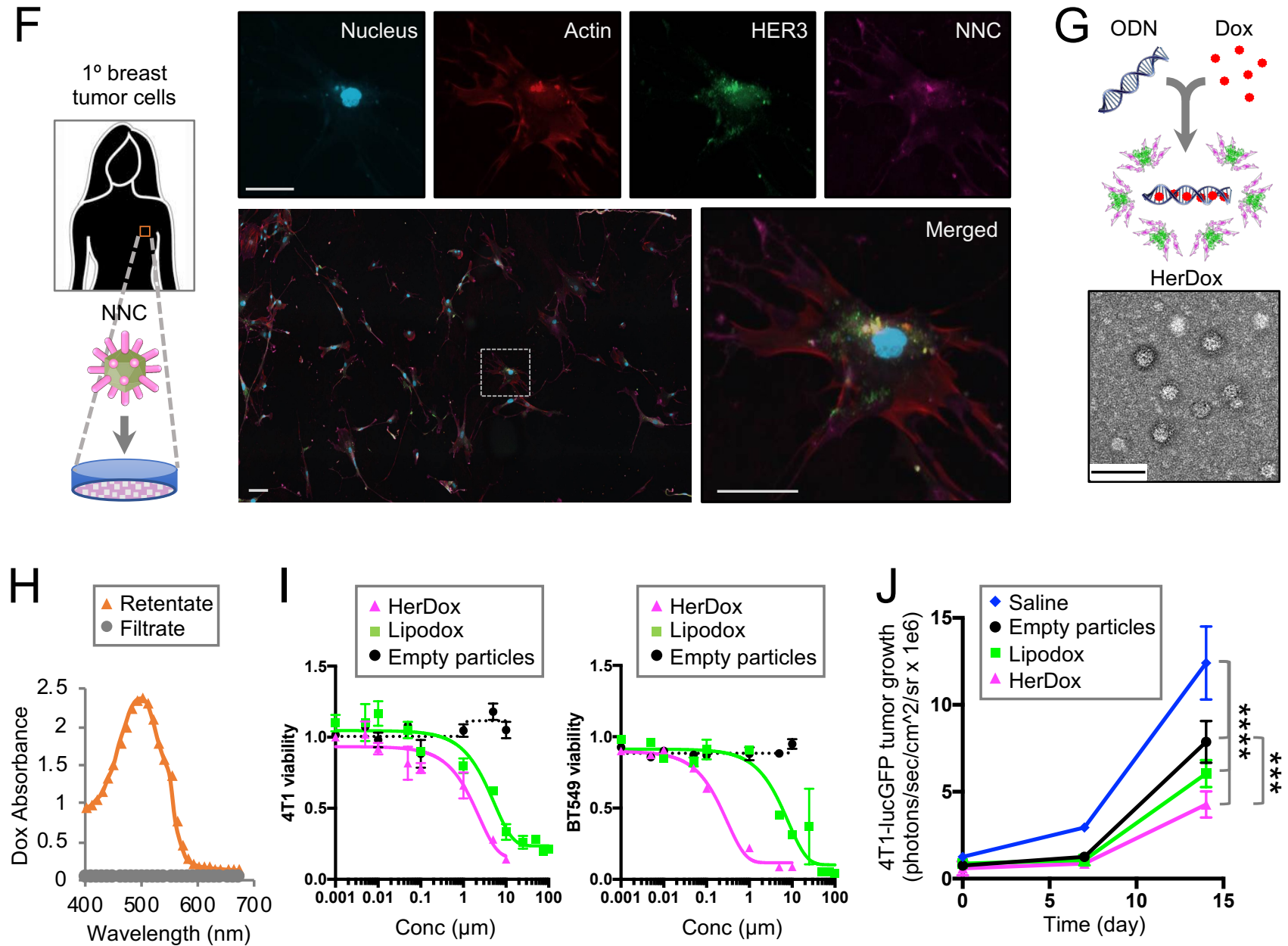
Figure 2. Formation of HER3-targeting nano-nucleocapsids (NNCs). A, NNC assembly

871 nucleated by the cargo-driven convergence of capsomeres. Inset, TEM of NNCs. Scale bar $100 \mathrm{~nm}$. B,

872 ITC of ssODN binding to HPK. Top panel, raw thermogram. Lower panel, binding isotherm. Inset,

873 signature plot summarizing the thermodynamics parameters of the reaction (inserted table). C,

874 Hydrodynamic diameters of NNCs containing ssODN (HPK-ODN) compared with HPK alone, as

875 determined by DLS. D, Fluorimetry of NNCs containing NIR-labeled oligodeoxynucleotide (NIR-ODN)

876 after filtration to isolate assembled particles (retentate) from unassembled NIR-ODN (filtrate). E, Serum-

877 protection assay, showing gel electrophoresis and ethidium bromide staining of dsODN after incubation

878 in serum nucleases (nuc) -/+ pre-assembly with HPK. H.I., heat-inactivated serum. F, Binding of HPK

879 particles to patient-derived tumor cells isolated from dissociated tissue freshly acquired from a HER2+

880 patient. The delineated region is enlarged in the top row and the lower right panel. All scale bars, $25 \mu \mathrm{m}$.

881 G, HerDox assembly and TEM of HerDox (inset). Scale bar, $80 \mathrm{~nm}$. H, Spectrophotometric absorbance

882 of HerDox after filtration of isolated assembled particles (retentate) from unassembled Dox (filtrate). I,

883 Killing curves on mouse (4T1) and human (BT549) TNBC lines, comparing HerDox to Lipodox and empty

884 (no Dox) NNCs at 24h after treatment. Cytotoxicity was measured by crystal violet staining following

885 standard procedures. $\mathrm{n}=3$ independent experiments performed in triplicate. J, Growth of subcutaneous

886 bilateral 4T1 tumors (reflected by tumor bioluminescence) in BALB/c mice during systemic treatment with

887 indicated reagents (regimen described in Supplementary Methods). Day 0, first day of treatment (5

888 days after tumor implantation). ${ }^{* * *} p=0.0005,{ }^{* * * *} p<0.0001(n=5)$.

889

890 
Figure 3. Systemic NNCs enter mouse brain parenchyma.

A

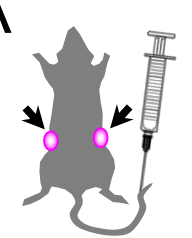

NU/NU-JIMT1

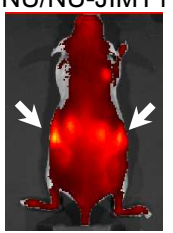

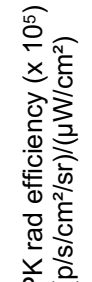

$$
\text { 모 }
$$

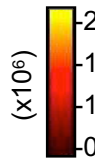

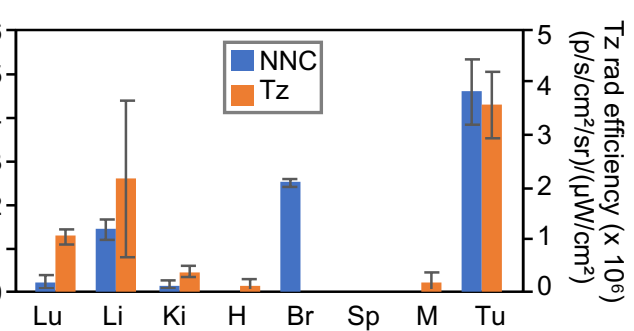

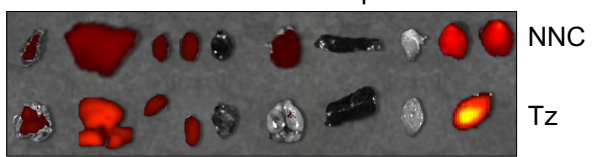

B

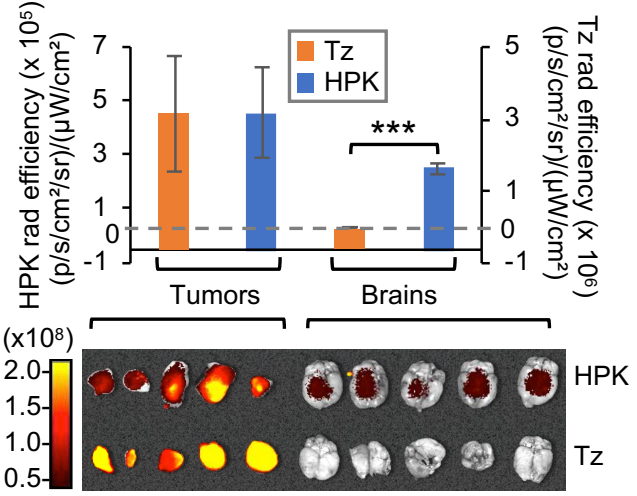

C
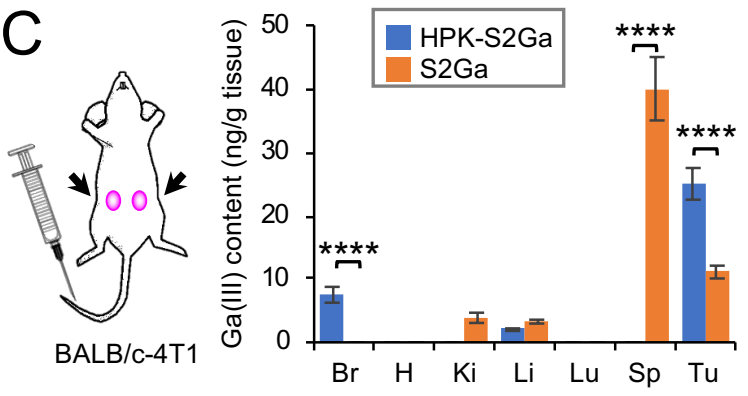

D

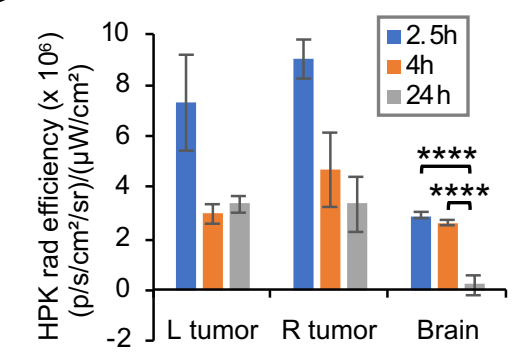

$E$
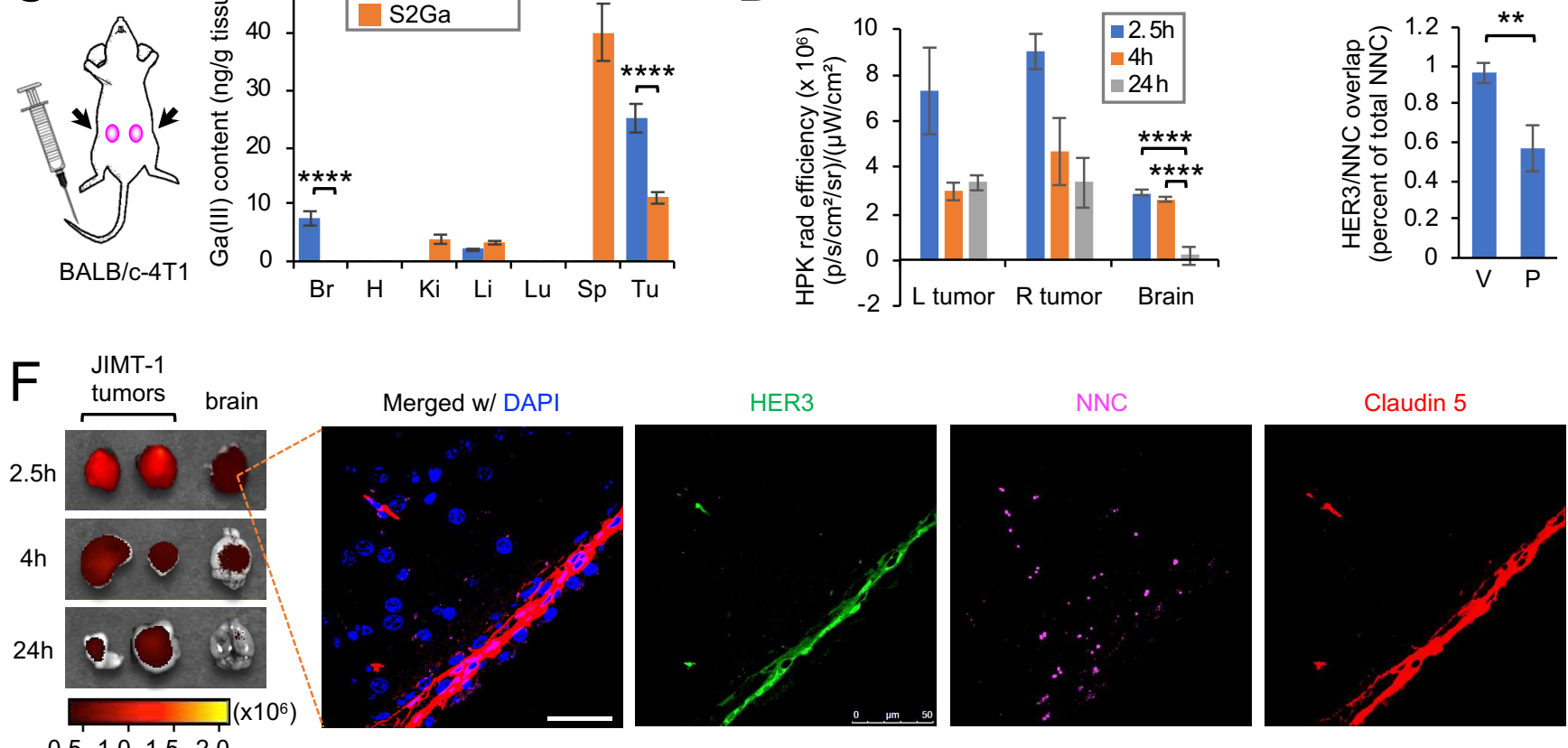

$G$

Merged, BF,

NIR-ODN

HPK
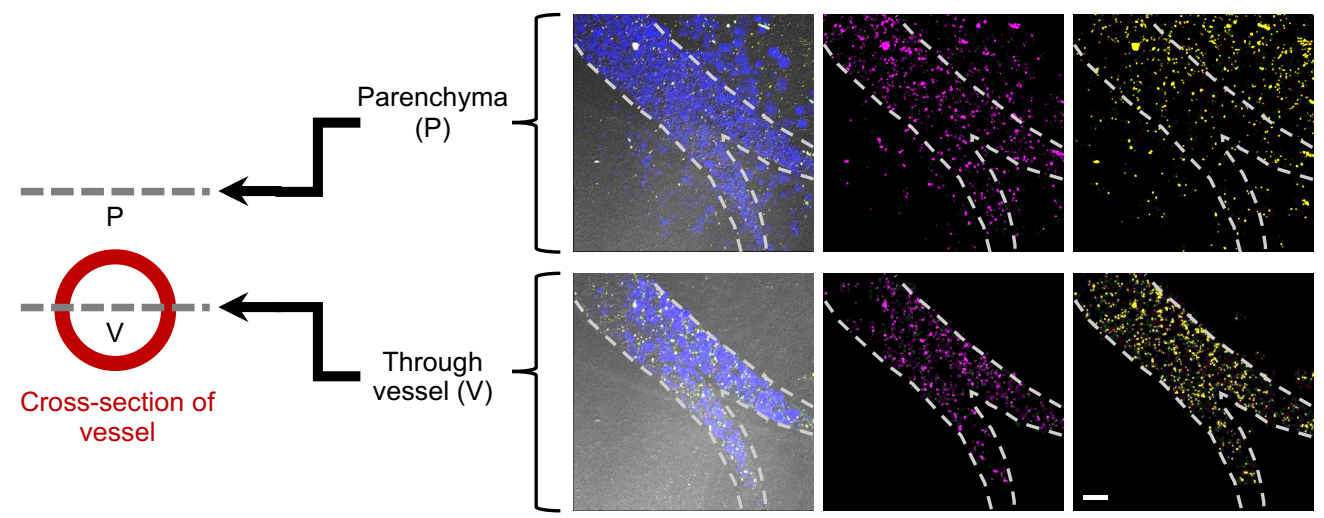

HPK-ODN Free ODN

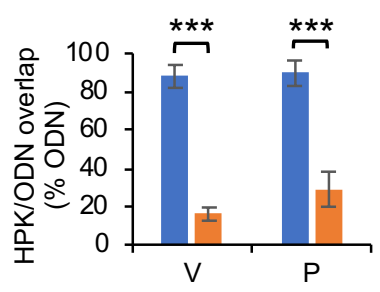

892 
Figure 3. Systemic NNCs enter mouse brain parenchyma. A, Tissue-distribution of NIR-

895 labeled NNCs or Tz at $4 \mathrm{~h}$ after systemic delivery in mice bearing subcutaneous JIMT-1 breast tumors.

896 Arrows, tumor locations. Lu, lung; Li, liver; Ki, kidney; $\mathrm{H}$, heart; Br, brain; Sp, spleen; M, muscle; Tu, 897 tumor. ( $\mathrm{n}=5$ mice/treatment) B, Brain and tumor distribution of NIR-labeled HPK or Tz at 2.5h after 898 systemic delivery in mice bearing subcutaneous JIMT-1 breast tumors. ${ }^{* *} \mathrm{p}<0.001$ ( $\mathrm{n}=5 \mathrm{mice} /$ treatment). 899 C, Tissue content of gallium(III)-metallated corrole (S2Ga) measured by ICP-MS at 6h after systemic 900 delivery alone or by HPK bioparticles in an orthotopic syngeneic mouse model of TNBC. ${ }^{* * * *} p<0.0001$ 901 ( $n=6)$. D, Quantification of tumor and brain distribution at indicated time-points after systemic 902 administration of NNCs delivering NIR-ODN in mice bearing subcutaneous JIMT1 tumors. ${ }^{* * *} p<0.0001$ 903 ( $n=12)$. E, Quantification of NNC and HER3 overlap in brain vessels (V) compared with the parenchyma 904 (P) from specimens represented by panel $\boldsymbol{F}$. ${ }^{* *} \mathrm{p}<0.01(\mathrm{n}=3)$. Scale bar, $50 \mu \mathrm{m}$. $\mathbf{F}$, Image acquisition of 905 tumor and brain distribution at indicated time-points after systemic administration of NNCs delivering 906 NIR-ODN in mice bearing subcutaneous JIMT1 tumors. Enlarged specimens show NNC and HER3 907 localization relative to the brain vasculature (claudin 5 ) at $2.5 \mathrm{~h}$ after systemic delivery. G, Analysis of 908 HPK and NIR-ODN overlap in representative brain section from $\boldsymbol{F}$, showing adjacent z-axis planes that 909 transect the vessel $(\mathrm{V})$ and the parenchyma $(\mathrm{P})$ above the vessel. Free ODN, NIR-ODN without 910 overlapping HPK. Quantification shows the overlap of HPK with NIR-ODN at each location. ${ }^{* * *} \mathrm{p}<0.0005$ 911 ( $\mathrm{n}=3$ independent specimens). Scale bar, $20 \mu \mathrm{m}$.

912 
A

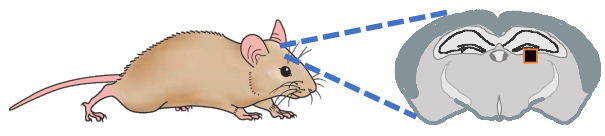

Mouse HER3
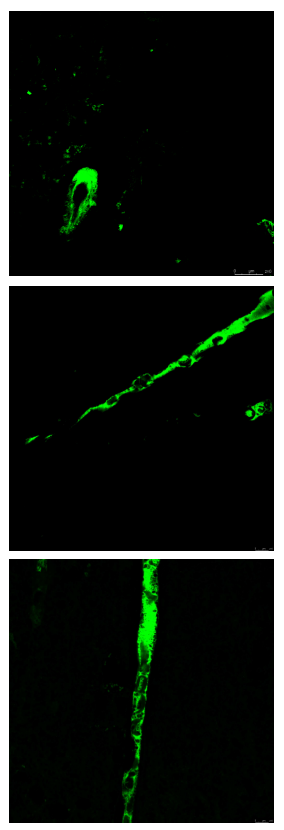

Mouse claudin 5

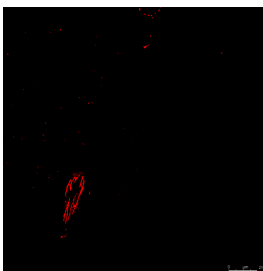

Merged w/ nucleus
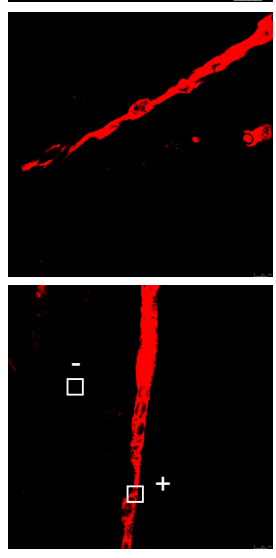

B

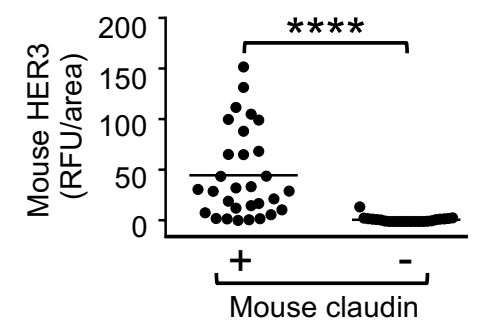

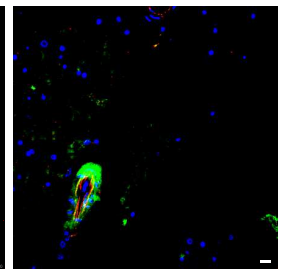

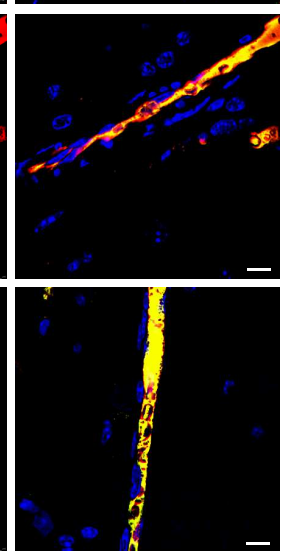

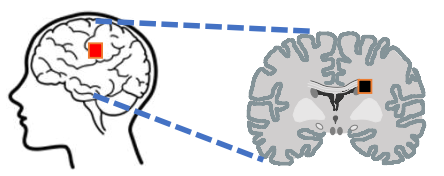

Human HER3

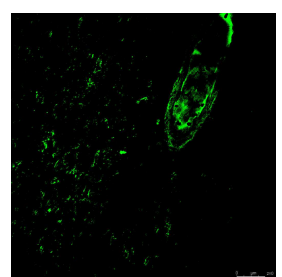

Human claudin 5

Merged w/ nucleus
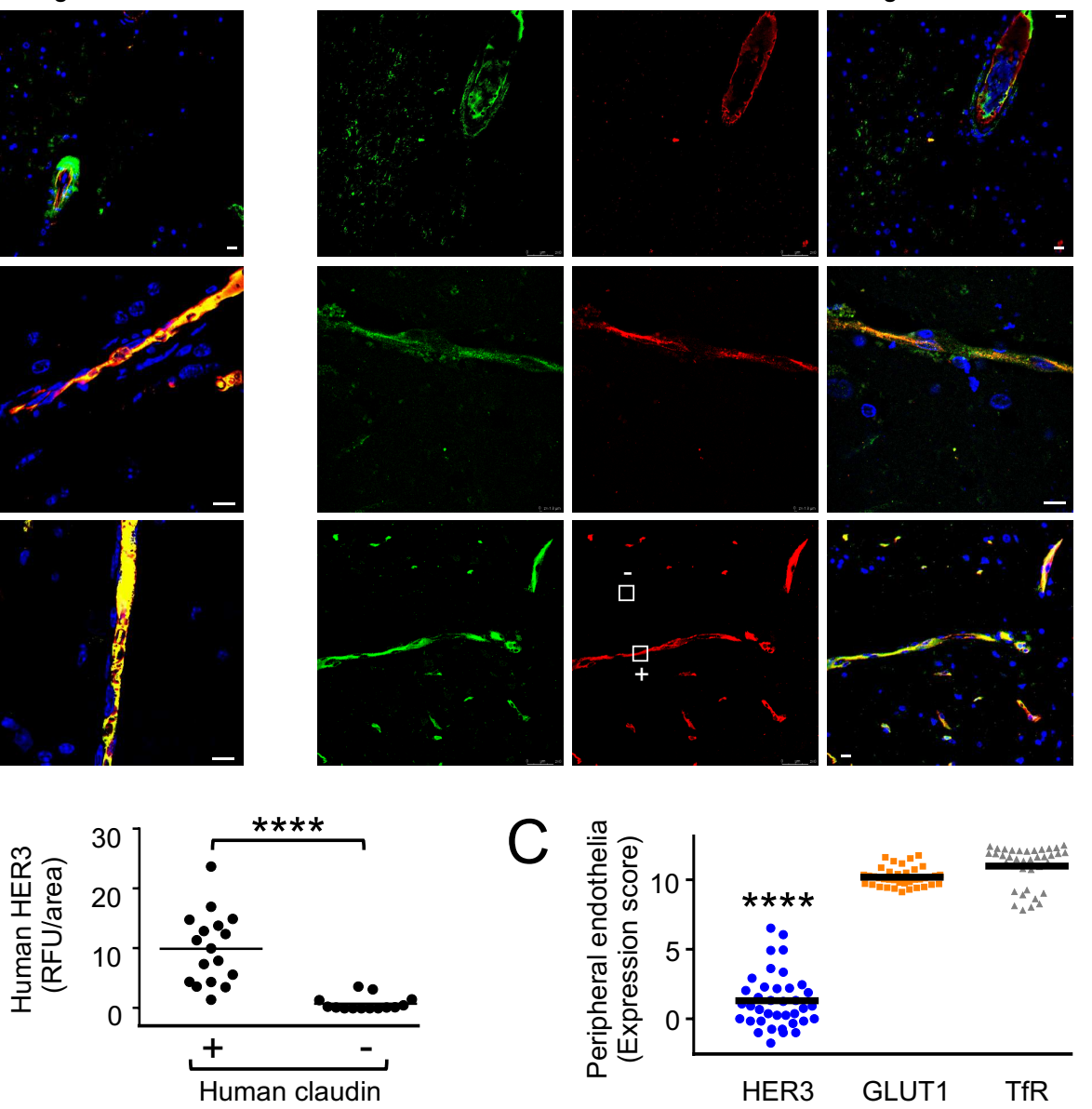

D
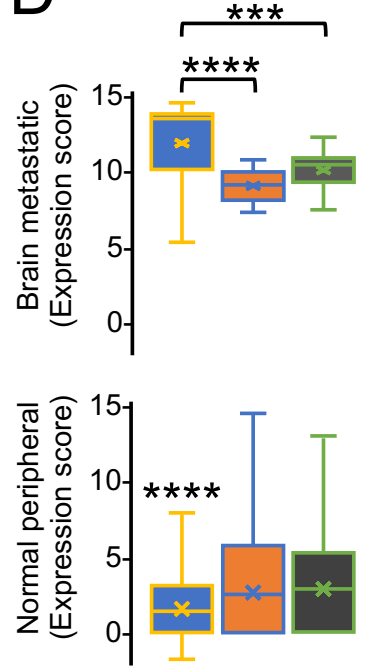

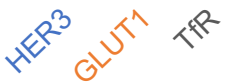

E

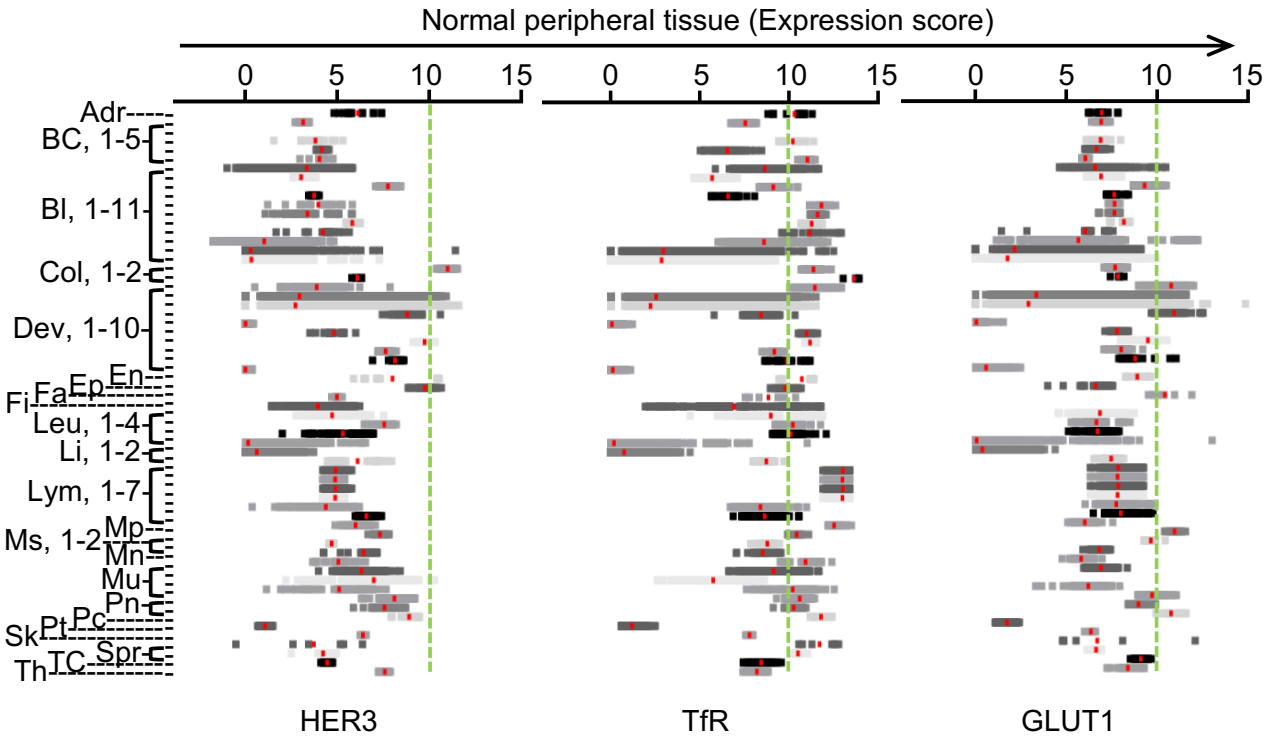


Figure 4. HER3 expression on the blood-brain barrier (BBB). A, Immunohistofluorescence of

917 frontal cortex from non-diseased adult murine and human brains showing cross-sections and longitudinal

918 views of blood vessels within brain specimens. Specimens were obtained from female adult

919 immunodeficient mice (6+ months) and adult human frontal cortex. White squares delineate claudin

920 positive (+) and negative (-) areas. Scale bar: $10 \mu \mathrm{m}$. B, Quantification of overlap between claudin-5 and

921 HER3 in specimens shown in $\boldsymbol{A}$. Data points represent the means of individual regions of interest in each

922 indicated zone. ${ }^{* * *} \mathrm{p}<0.0001$. C, R2 database analysis of HER3 (N=38), glucose receptor (GLUT1;

$923 \mathrm{~N}=38)$, and transferrin receptor (TfR; $\mathrm{N}=38$ ) expression in peripheral endothelial tissue. ${ }^{* * * *} p<0.0001$. $\mathbf{D}$, 924 R2 database analysis of HER3, GLUT1, and TfR expression in human breast cancer brain metastases

925 (upper graph) and human peripheral non-tumor tissues (lower graph). ${ }^{* * *} p=0.0006$, ${ }^{* * *} p<0.0001$,

$926 \mathrm{~N}=31,408$ per group. E, Itemized expression scores of human peripheral (non-brain) non-tumor tissues

927 comparing HER3, TfR, and GLUT1 gene expression. Red line in each category indicates mean. Dashed

928 vertical line delineates high expression threshold. Each y-axis tick mark represents a separate database.

929 Multiple databases within the same category are enumerated. Sources and $\mathrm{N}$ of each database are listed

930 in the Methods. Adr, adrenal; BC, B cell; BI, blood; Col, colon; Dev, developmental; En, endothelial; Ep,

931 epithelial; Fa, fallopian tube; Fi, fibroblasts; Leu, leukocytes; Li, liver; Lym, lymphocytes; Mp,

932 macrophage; Ms, mesenchymal; Mn, monocytes; Mu, muscle; Pn, pancreatic; Pc, placenta; Pt, platelets;

933 Sk, skeletal; Spr, spermatogonia; TC, T cells; Th, thymus.

934

935 

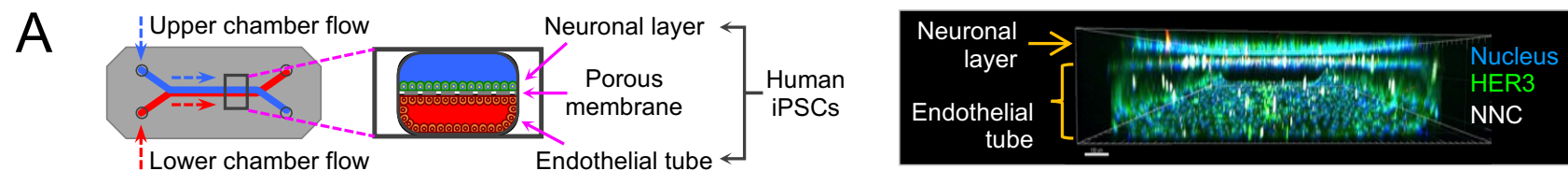

B
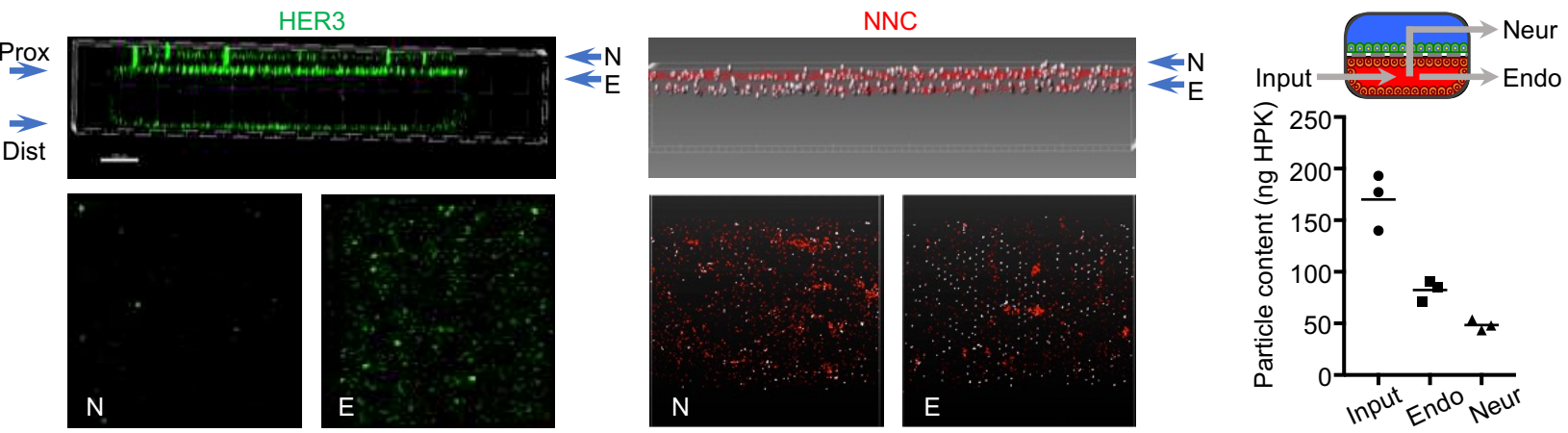

C
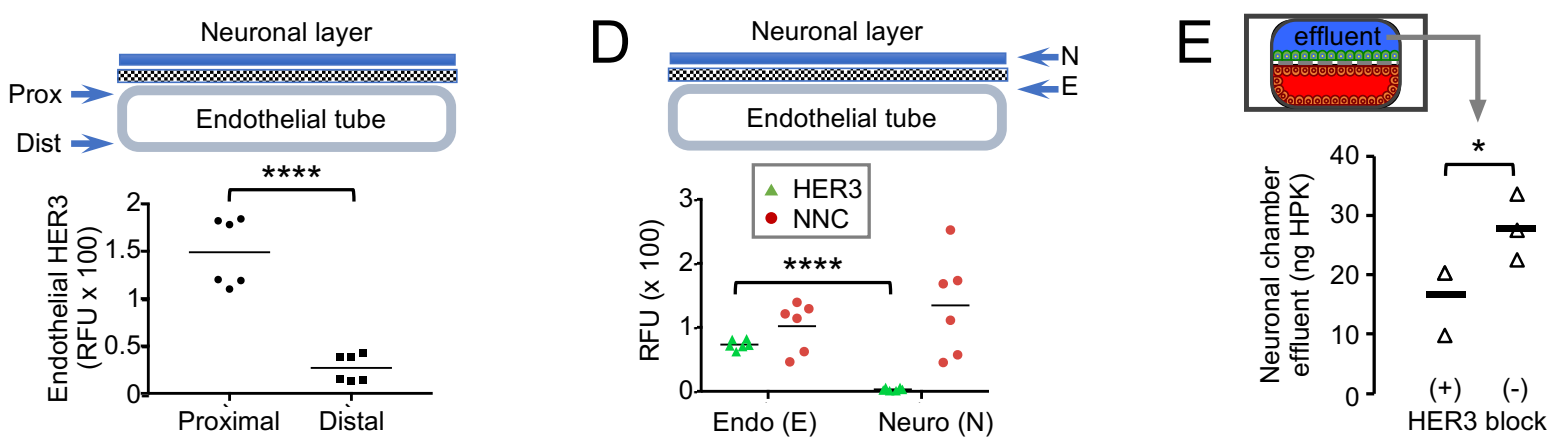

F

Neuronal layer
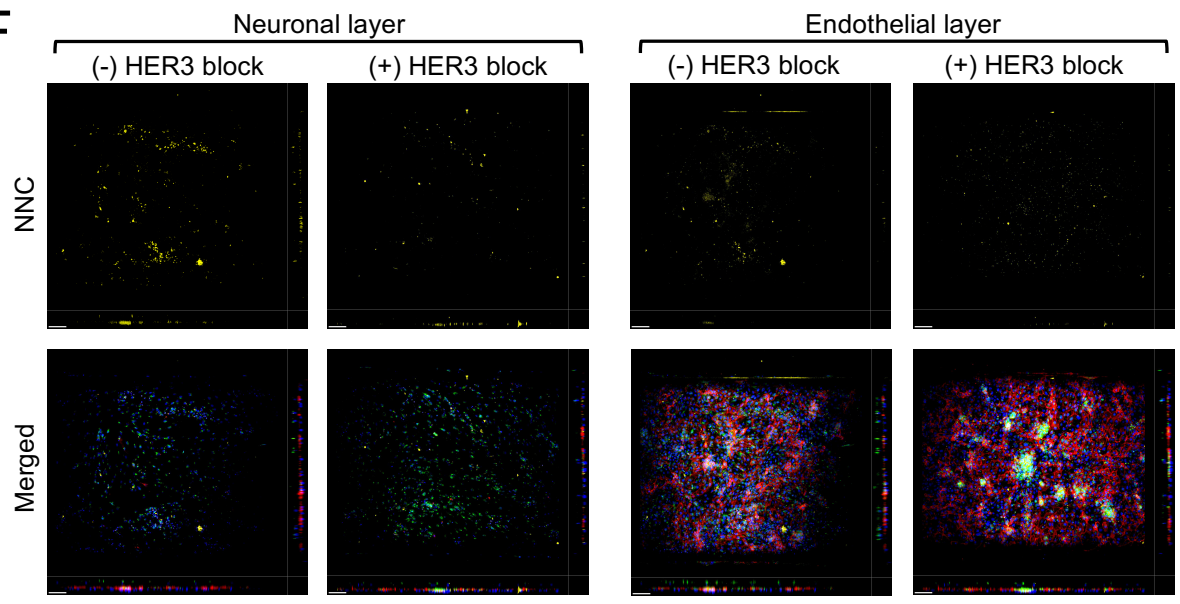

NNC, DAPI, HER3, Claudin 5

$G$
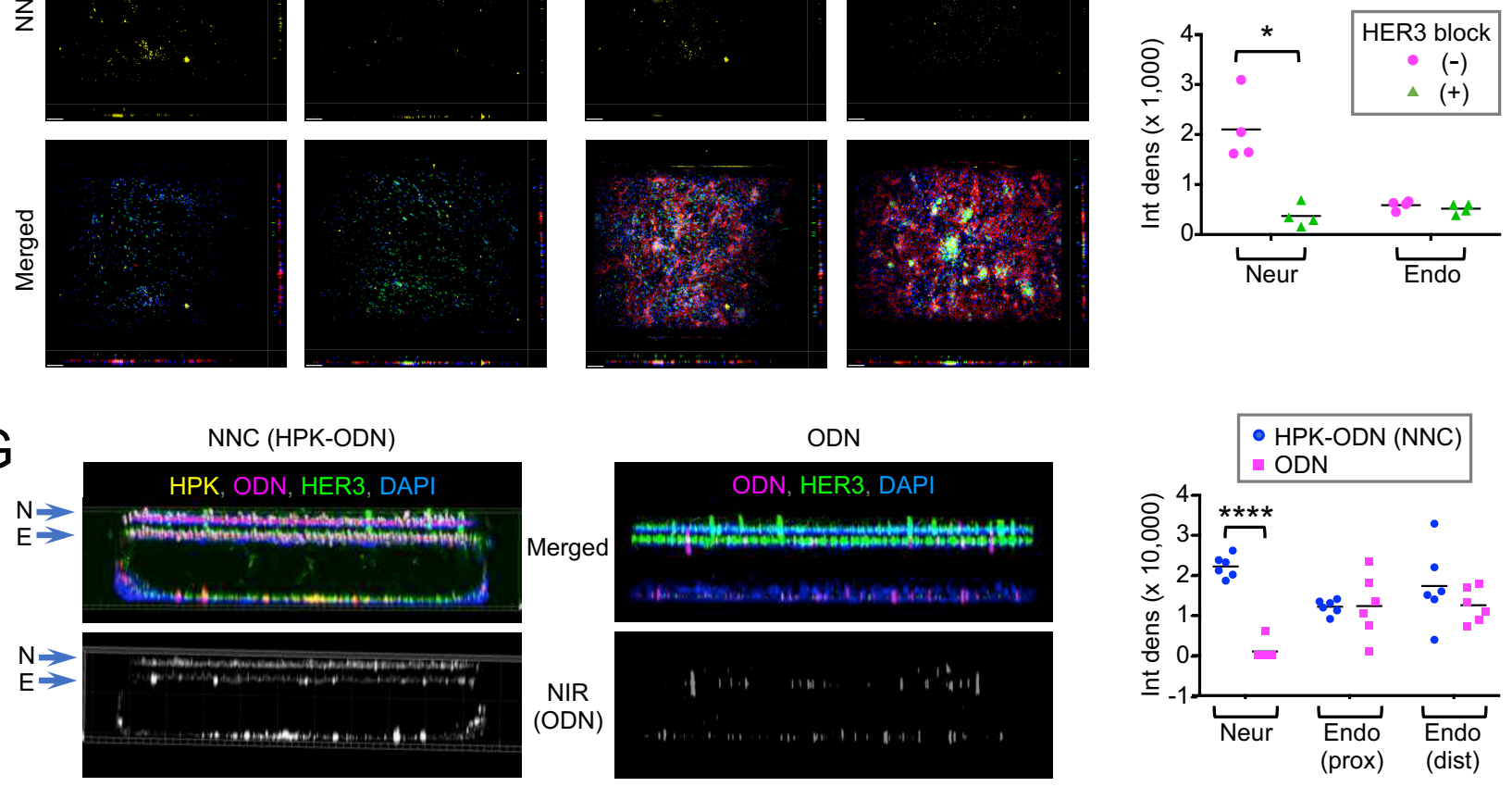
Figure 5. NNC transit in a reconstituted human BBB. A, Left, schematic showing BBB chip.

939 Right, 3D chip imaging $24 \mathrm{~h}$ after introduction of NNCs into the endothelial flow chamber. Scale bar, 150

$940 \mu \mathrm{m}$. B, Detection of HER3 and NNCs in BBB chips $4 \mathrm{~h}$ after injection of NNCs delivering NIR-ODN into

941 endothelial flow chamber. Images show cross-sectional and 2D surface views of neuronal $(\mathrm{N})$ and

942 endothelial (E) layers. Scale bar, $150 \mu \mathrm{m}$. Quantification of NNCs collected from endothelial (Endo) and

943 neuronal (Neur) chamber effluents. C, Relative HER3 levels on proximal and distal endothelium.

$944{ }^{* * * *} p<0.0001$. D, Relative levels of HER3 and NNC on endothelial tube (E) and neuronal layer (N).

$945{ }^{* * * *} p<0.0001$. E, Quantification of NNC content collected from neuronal chamber effluents during $4 \mathrm{~h}$ of 946 NNC flow into endothelial channel $-/+$ blocking of HER3. ${ }^{*} p<0.05$. F, Immunofluorescence detection of 947 NNCs in neuronal and endothelial layers after $4 \mathrm{~h}$ of NNC flow into the endothelial micro-chamber -/+ 948 HER3 blocking. Top panels, NNC fluorescence channel alone. Lower panels, merged fluorescence 949 channels. Scale bar, $150 \mu \mathrm{m}$. Quantification shows integrated signal densities of NNCs in neuronal and 950 endothelial compartments -/+ HER3 blocking. ${ }^{*} p<0.05$. G, Comparison of NNCs delivering NIR-ODN 951 with NIR-ODN alone. Upper panels, merged fluorescence channels. Lower panels, NIR channel.

952 Quantification shows integrated signal densities comparing NIR-ODN -/+ HPK in neuronal layer, 953 proximal endothelium, and distal endothelium. ${ }^{* * *} p<0.0001$ ( $n=6$ independent fields). 
Figure 6. NNCs target and reduce intracranial tumors after systemic delivery.

A $\begin{gathered}4 T 1- \\ \text { LucGFP }\end{gathered}$

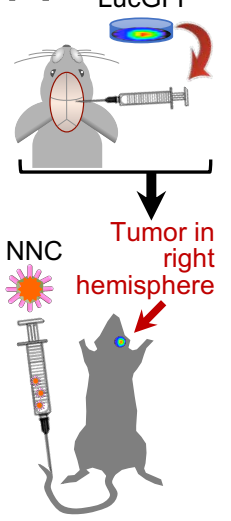

Luc imaging

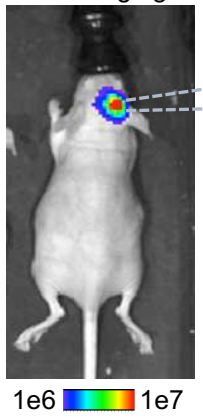

Lum

$\left(\mathrm{p} / \mathrm{s} / \mathrm{cm}^{2} / \mathrm{sr}\right)$
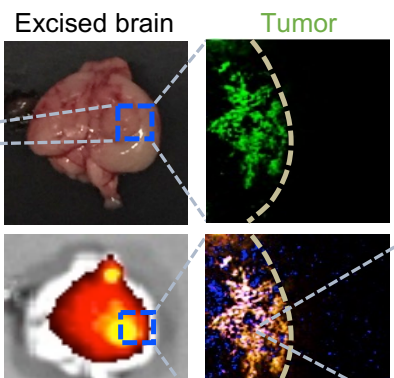

NNC imaging

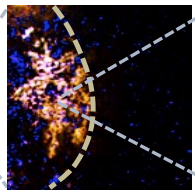

5 e5 2e6 Nucleus, NNC NIR $\left(\mathrm{p} / \mathrm{s} / \mathrm{cm}^{2} / \mathrm{sr}\right) /\left(\mu \mathrm{W} / \mathrm{cm}^{2}\right)$

C
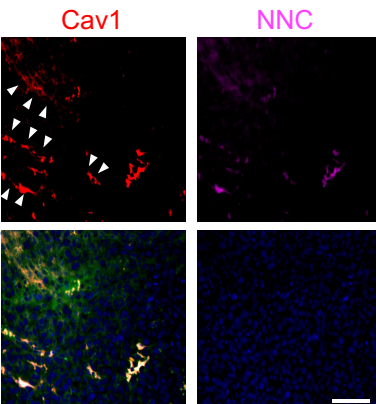

Merged, tumor

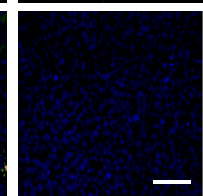

Nucleus

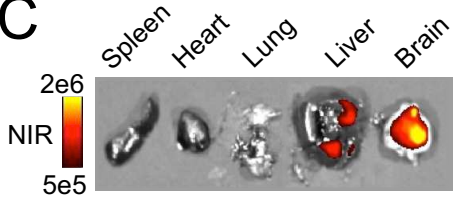

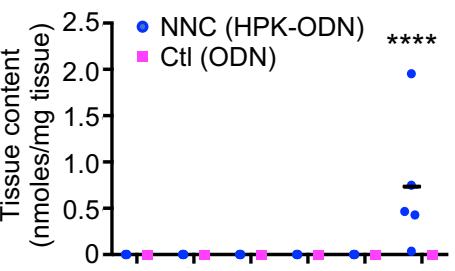

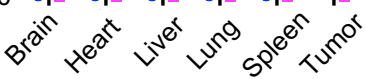

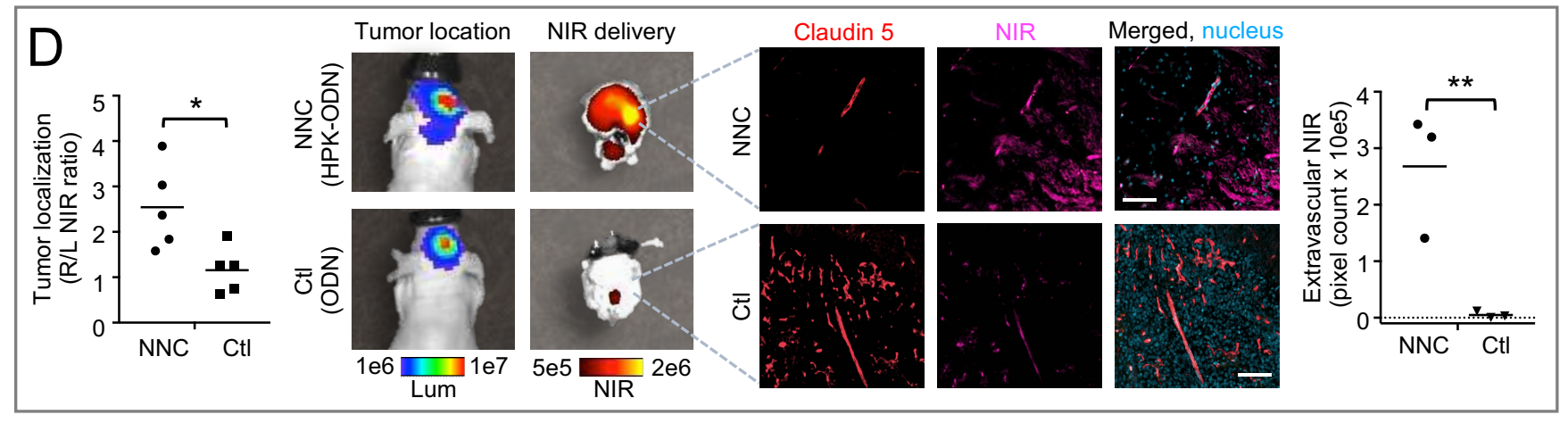

E

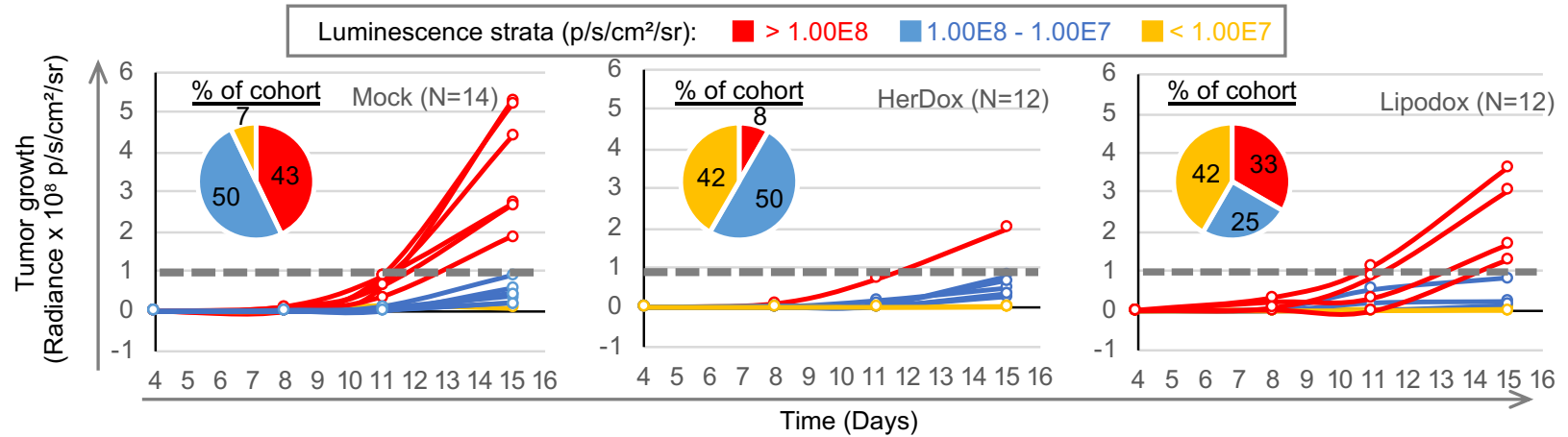

F Day 4 Day 8 Day 11 Day 15
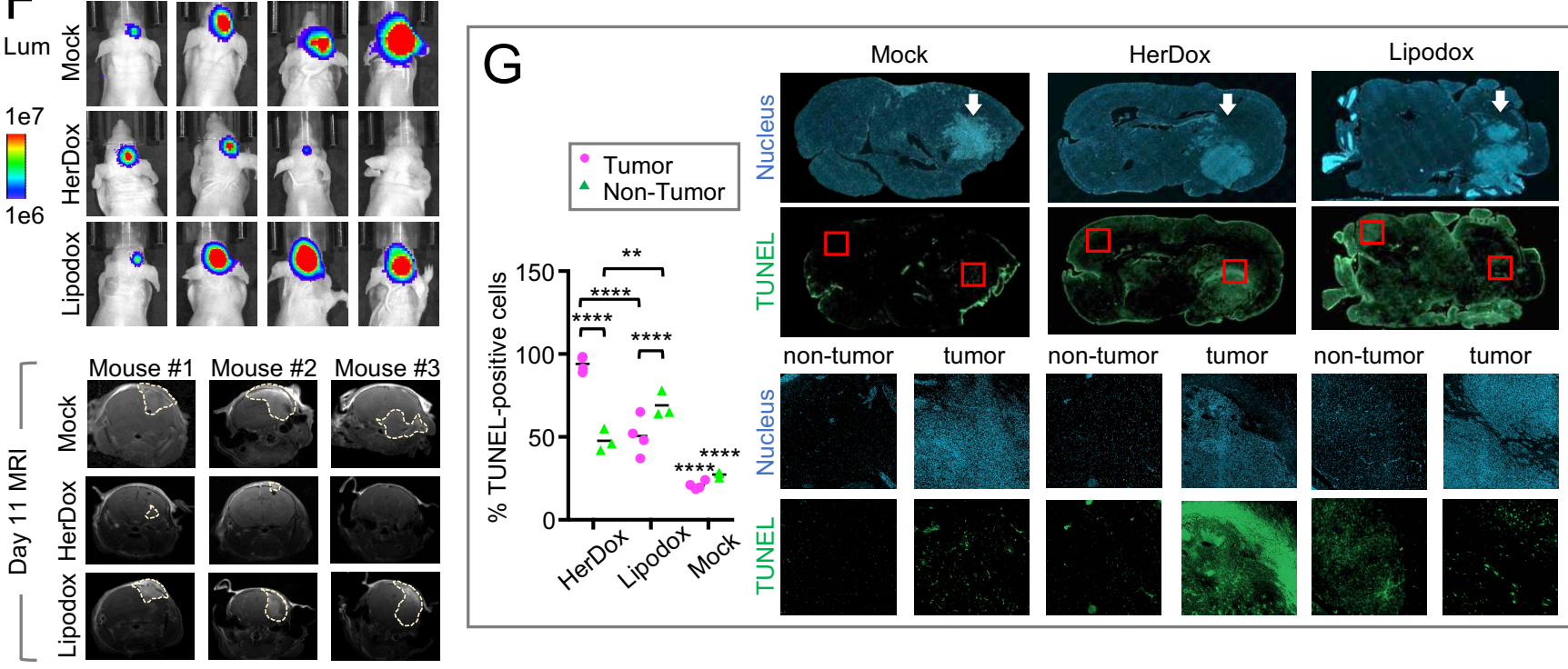
Figure 6. NNCs target and reduce intracranial tumors after systemic delivery. A, Schematic

959 showing brain localization of each stereotactic tumor implant in mice receiving systemic NIR-ODN NNCs

960 or control reagents (NIR-ODN) 8 days post-implant. Tissue harvested $4 \mathrm{~h}$ after systemic delivery are

961 shown in $\boldsymbol{B}-\boldsymbol{D}$. B, Immunohistofluorescence of brain sections showing localization of NIR-ODN after tail

962 vein injection of NNCs. Brain specimens from representative mouse include IC tumor. Cav1, caveolin 1.

963 Scale bar, $35 \mu \mathrm{m}$. C, Quantification shows tissue-distribution of systemic NNCs (inset) and comparison

964 to NIR-ODN. ${ }^{* * *} p<0.0001$ ( $n=5$ mice/treatment). D, Comparison of NIR-ODN NNCs and NIR-ODN in

965 brain and IC tumor regions after systemic delivery. Left graph, tumor localization ( $\mathrm{N}=5$ mice/ treatment

966 group). Images show enlarged views of tumor regions with NIR distribution shown in comparison to

967 claudin 5-positive vasculature. Scale bar, $35 \mu \mathrm{m}$. Right graph, quantification of extravascular (non-

968 overlapping with claudin-5) NIR comparing mice receiving NNC and control reagents. ${ }^{*} p<0.05,{ }^{* *} p<0.01$

969 (n=3). E, IC tumor growth in mice receiving HerDox, Lipodox and mock-treatments. Each growth curve

970 is designated a color based on accelerated growth (shown in red), slow tumor growth (blue), and no

971 detectable tumor growth (yellow). F, BLI and MRI of representative mice from each cohort treated in $\boldsymbol{E}$.

972 G, Detection of apoptosis by TUNEL stain in brain specimens from mice in each cohort treated in $\boldsymbol{E}$.

973 Channel-separated images show tumor and non-tumor areas. ${ }^{* *} p<0.01 .{ }^{* * * *} p<0.0001$ ( $n=3$ independent 974 fields each averaging 227 cell events).

975

976 


\section{Supplementary Files}

This is a list of supplementary files associated with this preprint. Click to download.

- SUPPLEMENTARYMATERIALSv8.pdf 